

\section{Next generation sequencing-based exploration of genomes and transcriptomes of medicinal plants}

Saurabh Chaudhary, 1

Prakash C. Sharma, ${ }^{*} *$

Email prof.pcsharma@gmail.com

1 University School of Biotechnology, Guru Gobind Singh Indraprastha University, Dwarka 16C, New Delhi, 110078 India

\section{Abstract}

Medicinal plants are known for their therapeutic potential and have been associated with human history for their use in traditional medicine systems in different countries. Recent advances in next generation sequencing (NGS) technologies have accelerated research on medicinal plants with reduced cost and efforts. NGS technologies not only provide opportunity for high throughput whole genome sequencing, they also facilitate direct RNA sequencing. The sequence data-sets generated can further be explored for application in various areas of research such as comparative genomics, data mining for small and long non-coding RNAs, mining of molecular markers, gene discovery, etc. Continuous efforts are being made by commercial sequencing service providers in improving technology to overcome bioinformatics challenges in NGS data analysis. In recent past, genome sequence projects on various medicinal plants have been successfully accomplished and few others are in pipeline. Similarly, enormous NGS-based transcriptome data have been generated in a number of medicinal plants. In the present review, we have briefly attempted to address advancement in NGS technology, 
genomic and transcriptomics studies on medicinal plants with special emphasis on seabuckthorn (Hippophae sp.), a medicinally important plant of Indian Himalayas. Moreover, the scope of implementation of NGS based research on medicinal plants have been explored for the selection of candidate genes involved in particular biosynthesis pathways. The identified genes can be exploited for engineering medicinal plants for producing improved quality biologically active phytocompounds.

\section{Keywords}

Medicinal plants

Next generation sequencing

Genome

Transcriptome

Seabuckthorn

\section{Introduction}

Many plants are used for therapeutic, medicinal and nutritional purposes from ancient time in different countries worldwide. In recent past, research on medicinal plants has significantly grown because of acceptance of the use of phytomedicines over synthetic drugs for treatment of various diseases. Plants produce thousands of metabolites having diverse medicinal uses. Over 12,000 phytocompounds having biological activity have been identified and isolated from different plants and their parts. Further, this number represents roughly $10 \%$ of the projected useful compounds, suggesting the need of exploring more medicinal plants for their pharmacological benefits (Lai and Roy 2004). The use of medicinal plants to treat various diseases is predated human history and widely used in non-industrialized societies. However, the increased global consumption of phytomedicines to fight against various infectious and other diseases has rightly stimulated extensive research on medicinal plants aiming to facilitate production of improved quality phytocompounds and making it 
important activity of pharmacological and pharmaceutical sector (Sumner et al. 2015). Moreover, research advancement in the molecular biology techniques specially sequencing technique has revolutionized research on medicinal plants. Studies have been conducted on medicinal plants at genome and transcriptome level allowing identification of key genes involved in the production of bioactive phytocompounds. The emergence of next generation sequencing (NGS) techniques led to the deep understanding of the biosynthesis pathways of biologically active phytocompounds after availability of enormous genomic/transcriptomics sequence data (Sharma and Shrivastava 2016). Comparative genomics, expression analysis, homology search, functional annotation, and phylogenetic analysis further facilitate the identification of genes involved in the production of secondary metabolites and biochemical pathways in medicinal plants.

The advent of NGS has driven the genomic/transcriptomics based inquiries in biology where high throughput sequence reads are generated with less labor and low cost. NGS not only facilitates the genome sequencing, but recent advancements have led to the developments allowing genome resequencing, transcriptome sequencing (RNA-Seq), Chip sequencing (DNA-protein interactions analysis), and epigenome analysis (de Magalhaes et al. 2010). Various NGS technologies include single molecule real-time sequencing (Pacific Biosciences), ion semiconductor (Ion Torrent Sequencing), pyrosequencing (Roche 454), sequencing by synthesis (Illumina), and sequencing by ligation (SOLiD sequencing) (Shendure and Ji 2008; Maclean et al. 2009; Metzker 2010; Mardis 2013). Among all NGS technologies, Pacific Biosciences platform provides the longest read length followed by Roche-454 platform which further has been widely used in transcriptome (RNA-seq) of various non-model plant species. Availability of relatively long reads substantially reduce the de novo assembly challenges as compared to other sequencing platforms (Sun et al. 2010; Guo et al. 2010). Illumina is another highly utilized platform used for transcriptome analysis of various non-model organisms due to its potential for high sequence yield, though, efforts to increase its read length 
in underway, its short reads creates challenges for various bioinformatics analysis.

Remarkable progress has been made to explore medicinal plants at genomic/transcriptomic level for the ultimate goal of identify genes involved in biologically active phytocompounds and related pathways through NGS technologies. In the current article an attempt is made to review the application and contribution of NGS technologies in exploring medicinal plants with focus on seabuckthorn (Hippophae sp.), an important plant species of Indian Himalayas, having enormous medicinal, nutritional and therapeutic potential.

\section{Next generation sequencing technologies}

The first generation sequencing (FGS) technology was developed originally by two groups, Sanger et al. (1977) used chain-terminating inhibitors and Maxam and Gilbert (1977) used chemical degradation strategy. Later, advancement in the sequencing technologies led to the advent of second and third generation sequencing technologies which are collectively called as NGS technologies. The main focus of advancement in sequencing strategies demand for fast and low cost high throughput sequencing. In NGS large amount of sequencing data with millions of reads can be generated in parallel. NGS technologies may be useful for a variety of analysis including genome annotation, discovery of alternative isoforms, and gene expression profiling. Moreover, the technology has also helped researchers to gain deep insight into the mechanisms underlying processes in secondary metabolites biosynthesis, and development of genomic resources for diversity analysis, evolutionary analysis and marker assisted improvement of non model but important plant species (Shendure and Ji 2008; Maclean et al. 2009; Metzker 2010; Mardis 2013; Unamba et al. 2015). Different NGS platforms are based on variable chemistries and methods. The commonly used platforms of NGS and Sanger Sequencing are compared on the basis of chemistry used, read length, accuracy along with advantages and disadvantages in Table 2 . 


\section{Second generation sequencing}

The first commercially available NGS system 454-Roche uses pyrosequencing technology, which is based on detection of pyrophosphate released during nucleotide incorporation (Berka et al. 2010). Initially, the read length generated in 454-Roche was $100-150 \mathrm{bp}$, with data generated around $20 \mathrm{MB}$ per run from $>200,000$ reads. The performance of 454-Roche was drastically enhanced by the introduction of 454 GS FLX Titanium system in 2008. The read length increased up to 700-1000 bp with more accuracy and approximately 0.7-14 GB data per run (Liu et al. 2012). The biggest advantage of 454-Roche has been its speed, however, the high cost of reagent and instrument pose discouragement for 454-Roche system. The other NGS platform frequently used for various genome/transcriptome analyses is Illumina, earlier known as Solexa Genome Analyzer (GA). Solexa released its first instrument in 2006 with name Genome Analyzer (GA) which was later taken over by Illumina in 2007. The chemistry used by Illumina exploits sequencing by synthesis (SBS) approach. Initially, the output of GA was 1 GB per run which reached up to $200 \mathrm{~GB}$ per run with introduction of HiSeq 2000 platform by Illumina. Though continuous efforts were made to increase the read length in Illumina from 75 to $300 \mathrm{bp}$, still lesser than 454-Roche. However, the other advantages which makes Illumina platforms as a choice for transcriptome analysis is its potential to generate large amount of data, and lesser cost of reagents and instruments (Quail et al. 2012). The third generation NGS platform named as SOLiD was introduced by Applied Biosystems in 2006. SOLiD exploits Synthesis by Oligo Ligation Detection (SOLiD) chemistry. Initially the read length in ABI SOLiD System was 35 bp with 3 GB data per run and high accuracy of $99.85 \%$ (Mardis 2008). Though later in 2010 to 2013, ABI SOLiD released five upgraded platforms from SOLiD to SOLiD 5500xl with improved read lengths up to $85 \mathrm{bp}$, amount of data generated $30 \mathrm{~GB}$ per run, and accuracy of 99.99\%. However, the short read lengths and expensive computational analysis continue to be a major drawback as compared to other NGS platforms (Liu et al. 2012 ; Quail et al. 2012). Ion Torrent Systems Inc. of 
Life Technologies has developed semiconductor detection based system, another widely used NGS platform. The read length generated in Ion Torrent is 200-400 bp with 98\% accuracy. Though its low cost and high speed is the major advantage, detection of unwanted electronic signals due to homopolymer errors remain its major disadvantage (Rusk 2011).

\section{Third generation sequencing}

The recent advancements in the field of NGS include technologies developed within last 5 years with the generation of single molecule sequencing (SMS) systems. These are considered as third generation sequencing technologies and include: (i) Heliscope single molecule sequencing by Helicos Biosciences, (ii) Single molecule real time (SMRT) sequencing by Pacific Biosciences, (iii) Nanoball sequencing by Complete Genomics, and (iv)Nanopore sequencing by Oxford Nanopore Technologies. The concept used in third generation sequencing is to sequence and detect single molecule at a time with generation of longer reads proved to be beneficial for NGS technologies, as it magnificently enhanced data generation (Schadt et al. 2010; Thompson and Milos 2011). The first commercially used sequencing platform for SMS technology was Heliscope of Helicos Biosciences Subsequent introduction of PacBio RS platform by Pacific Biosciences, detects the fluorescent label dNTPs in real time manner and the technology has been named as single molecule real time (SMRT) sequencing. The technology further got revolutionized by nanopore sequencing of Oxford Nanopore Technologies where signal detection based upon SMS approach with nano sized pores (Schneider and Dekker 2012). Though the use of third generation sequencing technologies provides number of benefits in terms of potential, read length, amount of data generated, low cost over first and second generation sequencing. Continuous efforts are being made by commercial sequencing providers to overcome the drawbacks faced while using third generation sequencing such as moderate throughput, and bioinformatic challenges to analyze large amount of data (Schadt et al. 2010; Thompson and Milos 2011).

Emerging trends in sequencing technology from chain termination based 
sequencing to single molecule sequencing (Fig. 1) have facilitated diverse genomic/transcriptomic research on medicinal plants. Sequence data generated from these technologies provide deep insight of genome/transcriptome of medicinal plants which can be subsequently exploited for the identification of key genes, and understanding processes and pathways for biosynthesis of biologically active phytocompounds.

Fig. 1

DNA sequencing technologies

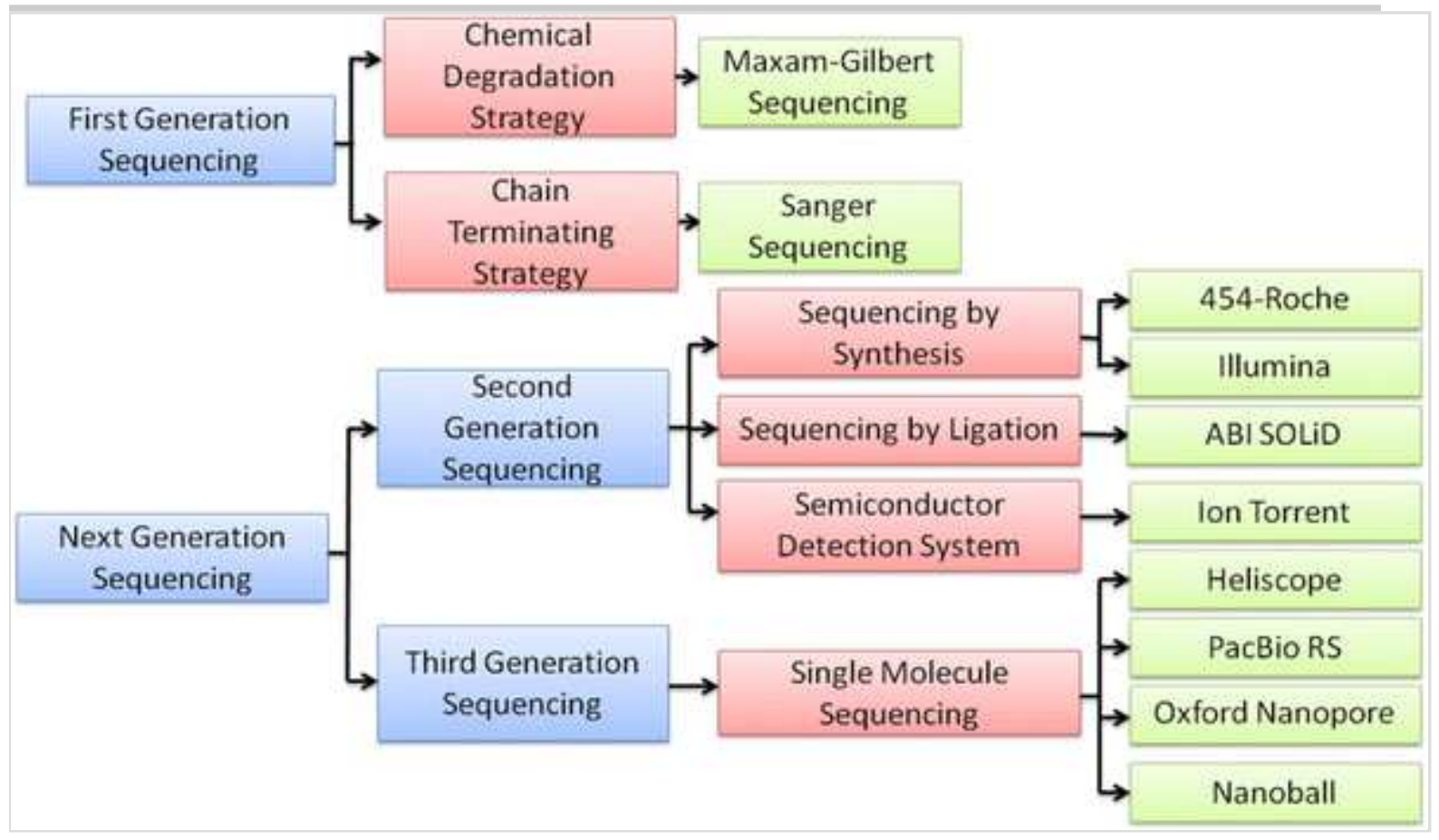

\section{NGS based research on medicinal plants}

Being rich in biologically active compounds, medicinal plants need to be first investigated at genomic/transcriptomic level. Subsequently, informative sequences and expression datasets generated can be used to characterize genes and biochemical pathways involved in biosynthesis of biologically active phytocompounds (Góngora-Castillo and Buell 2013). Research on medicinal plant genome/transcriptome level is also crucial for discovery of phytomedicines and development of plant pharmaceutical 
resources. Keeping the importance of genomic/transcriptomic data of medicinal plants, various studies have been conducted in recent past. In the following text, various genomic and transcriptomic projects on medicinal plants are briefly summarized with special emphasis on seabuckthorn, an important medicinal plant of high altitude regions of Eurasia.

\section{NGS based whole genome sequencing (WGS) studies in medicinal plants}

In the last 5 years, various NGS technology based whole genome sequencing projects on medicinal plants have been successfully accomplished. In China, a major project called "Herb Genome Project" was initiated with an aim to sequence whole genome and study secondary metabolite pathways of various medicinal plants (Chen et al. 2011). Similarly, National Institute of Health $(\mathrm{NIH})$ initiated the research on medicinal plants genome/transcriptome at Michigan State University (Medicinal Plant Genomics Resource) to identify the genes involved in secondary metabolite pathways (http://medicinalplantgenomics.msu.edu /index.shtml). Whole genome sequencing (WGS) studies provided deep insight into genetic and evolutionary frame work of medicinal plants. The sequence datasets generated may further be used for mining key genes, pathways, and molecular markers involved in biosynthesis of biologically active phytocompounds. Though genomic information is not available or little known for majority of medicinal plants, continuous efforts are made to accumulate more and more genomic resources for these non-model but important plant species. Studies carried out in recent years on different organeller genomes in medicinal plants are recently reviewed by Sharma and Shrivastava (2016). Some implications of NGS-based nuclear genomic studies on some traditionally used medicinal plants are summarized in Table 3.

The first NGS based nuclear genome information was provided in Cannabis sativa, a plant known for its medicinal and intoxicating properties. The genes and pathways related to cannabinoid biosynthesis 
were explored with generation of $534 \mathrm{Mb}$ draft genome of C. sativa (van Bakel et al. 2011). Similarly in the succeeding year, genomes of various traditionally used medicinal plants including Azadirachta indica, Capsicum annuum, Dendrobium catenatum, Elaeis guineensis, Juglans regia, Nelumba nucifera, Ocimum tenuiflorum, Prunus mume, Pyrus communis, Ziziphus jujube were sequenced (Table 3 ). The first genomic sequence draft of Azadirachta indica (Neem), the most commonly used medicinal plant was reported by Krishnan et al. (2012). Unlike other medicinal plants, the genome of $A$. indica is less complex comprising of 20,000 genes representing $364 \mathrm{Mb}$ genome, in comparison to the other medicinal plants having complex and larger genomes. For example, Ziziphus jujube genome sequence contains large number of repetitive elements constituting complex genome of $437.65 \mathrm{Mb}$ and 32,808 genes (Liu et al. 2014a, b). Thus, despite of many challenges in sequencing and assembling complex genomes, many whole genome sequencing project have been accomplished and many are underway, owing to revolutionary advances in sequencing technology and informatics tools. Nevertheless, immediate implications of NGS need to be important in the area of genome characterization, gene identification, comparative genomics, molecular markers mining, and more for development of value added phytomedicines (Sharma and Shrivastava 2016).

\section{NGS-based transcriptome sequencing studies in medicinal plants}

Most of the medicinal plants are considered as non model species but have some key elements with certain unique characteristics. The transcriptome research on medicinal plant has accelerated with the advancement in NGS technologies, particularly due to development of RNA sequencing either directly or through cDNA. Implementation of NGS technology in recent past has enabled identification of genes encoding certain unique characteristics in medicinal plants. Moreover, it also provides deep understanding of gene expression and underlying mechanism of secondary metabolites synthesis (Hao et al. 2012). Further, as the reference genome 
sequence information is not available for most of the medicinal plants, de novo transcriptome assembly of short sequence reads has served as an alternative for gene discovery, comparative analysis, expression analysis and identification of sequence variants (Góngora-Castillo and Buell 2013). The development of RNA-seq can further facilitate research through identification of novel transcripts involved in bioactive compound metabolism and in finding alternate splice forms of genes (Wang et al. 2009). A list of NGS based transcriptome studies in medicinal plants implemented in the last five years is summarized in Table 4 .

\section{Transcriptome studies to identify genes involved in biosynthesis pathways}

Primary aim of most NGS based transcriptomic studies in medicinal plants is to identify genes involved in biosynthesis of secondary metabolites or biologically active compounds. For example, transcriptome analysis of Allium sativum, a well known medicinal plant, aimed to identify genes involved in biosynthesis of organic sulfur (Sun et al. 2012a, b). Another case of Curcuma longa transcriptome profiling revealed abundance of transcripts related to ethanol metabolism and other important anticancer and anti-malarial terpenoids (Annadurai et al. 2013). Transcriptome analysis of Azadirachta indica, a most widely used medicinal plant, targeted the characterization of metabolic pathways involved in synthesis of bioactive compounds, comparative evolutionary studies and understanding of molecular pathways involved in the azadirachtin synthesis, the key component responsible for its medicinal value (Krishnan et al. 2012). Withania somnifera, is another example of this kind of research where NGS based transcriptome studies were performed to elucidate the key genes involved in tissue specific withanolide biosynthesis (Gupta et al. 2013, 2015). Transcriptome of Catharanthus roseus, was explored using NGS to develop metabolic pathways database “CathaCyc” (Van Moerkercke et al. 2013). It provides information about metabolic pathways, enzymes, proteins and genes involved in biosynthesis of various bioactive compounds. This type of database may have utility as 
a reference for the study of primary and secondary metabolism in medicinal plants including $C$. roseus. Other medicinal plants where genes involved in biosynthesis of certain bioactive compounds were targeted are listed in Table 4 . In some transcriptome studies, sequence data-sets were combined with metabolomic data-sets to reveal the complete picture of secondary metabolites. This approach termed as Phytochemical Genomics Approach has been used in various medicinal plants (Muranaka and Saito 2013; Sumner et al. 2015).

\section{Transcriptome sequence based comparative analysis in medicinal plants}

Digital gene expression (DGE) analysis is another process used in various transcriptome studies. Such type of studies in medicinal plants are performed for the identification of differentially expressed genes involved in secondary metabolites biosynthesis at different developmental stages or environmental conditions, as regulation of biosynthesis varies with species, developmental stages, environmental conditions and are tissue specific. For example, in case of Ocimum sp., a comparative analysis of two species $O$. sanctum and $O$. basilicum, was performed using NGS based transcriptome profiling (Rastogi et al. 2014). The study revealed significant difference in the differential pattern of genes related to secondary metabolites biosynthesis in two species. The data generated in this study may be useful in characterizing genes related to secondary metabolism, and for breeding special chemotypes in Ocimum sp. Other examples of transcriptome sequence based comparative analysis in medicinal plants include Digitalis purpurea, Ephedra sinica and Scutellaria baicalensis (Table 4).

Mining of small RNAs and molecular markers in transcriptome data

Transcriptome sequences generated by studies on many medicinal plants were also used for the mining of conserved and novel small RNAs and long non-coding RNAs, and development of molecular markers having 
applications in molecular breeding, marker assisted selection and QTL mapping. Transcriptome of Panax ginseng has been explored for the identification of novel and conserved microRNAs (miRNAs) (Wu et al. 2012).

The important data generated on transcriptomics of medicinal plants in recent past is likely to provide important leads for modern pharmaceutical industries towards development of herbal based medicines.

\section{NGS based transcriptome studies on seabuckthorn (Hippophae sp.)}

Seabuckthorn (Hippophae sp.), is a hardy, deciduous shrub that belongs to the family Elaeagnaceae. Seabuckthorn, a medicinally and economically important shrub of cold arid zones of high altitudes of Europe and Asia, particularly of Himalayas is also distributed in many other countries of Asia, Europe, South and North America. Since ancient ages, people of many countries of Asia and Europe have been using various parts of the seabuckthorn plant as a source of traditional medicine for effective treatment of various ailments. Extracts of seabuckthorn berries are commonly used for the treatment of skin diseases, jaundice, asthma, and for gastro-intestinal disorders (Singh et al. 2006). Medicinal and nutritional value of seabuckthorn is attributed to the presence of a variety of bioactive compounds in different parts of seabuckthorn i.e. berries, seeds, bark and leaves. Some of the important clinically proven medicinal properties include immunomodulatory, anti-inflammatory, and anti-cancer activity, hepatoprotective activity, anti-stress and adaptogenic activity, modulation of hypoxia-induced transvascular leakage, cardioprotective and anti-atherogenic effects, healing effect on acute and chronic wounds, anti-bacterial and anti-viral effects, anti-radiation effects (Geetha et al. 2008; Suryakumar and Gupta 2011).

In last decade, due to its high nutritional and medicinal value, seabuckthorn has attracted attention of many researchers worldwide. Moreover, the advancement in the field of NGS technology enhanced the 
research on transcriptomc level of this multipurpose medicinal plant. Several transcriptome studies were carried out on seabuckthorn using NGS with different aims and objectives, in recent years (Table 1). Fatima et al. (2012) studied the fatty acid composition of Canadian-grown cultivars (ssp. mongolica) and explored seabuckthorn seed transcriptome using the 454 GS FLX sequencing technology. They reported the presence of high content of linoleic and $\alpha$-linolenic acids in seed oil, while the pulp oil contained palmitoleic acid in abundance. Futher, they employed 454 GS FLX sequencing on seabuckthorn mature seeds which yielded 500,392 sequence reads, and reported 89,141 putative unigenes. Functional annotation and computational prediction of metabolic pathways indicated that primary metabolism and fatty acid and lipid biosynthesis pathways were highly represented categories in their data-sets.

\section{Table 1}

NGS based transcriptome studies in seabuckthorn (Hiipophae sp.)

\begin{tabular}{|c|c|c|c|c|c|}
\hline Aim & $\begin{array}{l}\text { Tissue } \\
\text { used }\end{array}$ & $\begin{array}{l}\text { NGS } \\
\text { platform }\end{array}$ & $\begin{array}{l}\text { Data } \\
\text { generated }\end{array}$ & Major finding & Referen \\
\hline $\begin{array}{l}\text { Fatty acid } \\
\text { composition } \\
\text { in seed; } \\
\text { identification } \\
\text { of genes and } \\
\text { enzymes } \\
\text { involved in } \\
\text { biosynthesis } \\
\text { of essential } \\
\text { oils }\end{array}$ & Seed & $\begin{array}{l}454 \mathrm{GS} \\
\text { FLX }\end{array}$ & $\begin{array}{l}89,141 \\
\text { putative } \\
\text { unigenes }\end{array}$ & $\begin{array}{l}\text { Seed oil of } \\
\text { Canadian-grown } \\
\text { sea buckthorn } \\
\text { cultivars } \\
\text { contains high } \\
\text { levels of } \\
\text { linoleic acid } \\
\text { and } \alpha \text {-linolenic } \\
\text { acid }\end{array}$ & $\begin{array}{l}\text { Fatima } € \\
\text { al. (201: }\end{array}$ \\
\hline $\begin{array}{l}\text { Complete } \\
\text { transcriptome } \\
\text { profiling }\end{array}$ & $\begin{array}{l}\text { Leaf } \\
\text { and } \\
\text { root }\end{array}$ & $\begin{array}{l}\text { Illumina } \\
\text { Hiseq } \\
2000\end{array}$ & $\begin{array}{l}53 \mathrm{Mb} \\
\text { transcriptome; } \\
88,297 \\
\text { unigenes }\end{array}$ & $\begin{array}{l}\text { Comprehensive } \\
\text { view of } \\
\text { seabcukthorn } \\
\text { transcriptome }\end{array}$ & $\begin{array}{l}\text { Ghangal } \\
\text { al. (201: }\end{array}$ \\
\hline $\begin{array}{l}\text { Mining of } \\
\text { microsatellites }\end{array}$ & $\begin{array}{l}\text { Leaf } \\
\text { and } \\
\text { root }\end{array}$ & $\begin{array}{l}\text { Illumina } \\
\text { Hiseq } \\
2000\end{array}$ & $\begin{array}{l}7.69 \% \\
\text { unigenes } \\
\text { harbored } \\
\text { microsatellite } \\
\text { repeats }\end{array}$ & $\begin{array}{l}\text { Microsatellite } \\
\text { dynamics in } \\
\text { seabuckthorn } \\
\text { transcriptome }\end{array}$ & $\begin{array}{l}\text { Jain et a } \\
\text { (2014) }\end{array}$ \\
\hline
\end{tabular}




\begin{tabular}{|c|c|c|c|c|c|}
\hline Aim & $\begin{array}{l}\text { Tissue } \\
\text { used }\end{array}$ & $\begin{array}{l}\text { NGS } \\
\text { platform }\end{array}$ & $\begin{array}{l}\text { Data } \\
\text { generated }\end{array}$ & Major finding & Referen \\
\hline $\begin{array}{l}\text { Differential } \\
\text { expression of } \\
\text { genes under } \\
\text { cold and } \\
\text { freeze stress }\end{array}$ & Leaf & $\begin{array}{l}\text { Illumina } \\
\text { Hiseq } \\
2000\end{array}$ & $\begin{array}{l}428 \\
\text { Differentially } \\
\text { expressed } \\
\text { genes }\end{array}$ & $\begin{array}{l}\text { Differentially } \\
\text { expressed genes } \\
\text { (DEGs) under } \\
\text { cold and freeze } \\
\text { stress }\end{array}$ & $\begin{array}{l}\text { Chaudhi } \\
\text { and } \\
\text { Sharma } \\
\text { (2015) }\end{array}$ \\
\hline
\end{tabular}

Table 2

Comparative analysis of different NGS platforms and Sanger sequencing technology (

\begin{tabular}{|c|c|c|c|c|}
\hline $\begin{array}{l}\text { NGS } \\
\text { platform }\end{array}$ & Chemistry & $\begin{array}{l}\text { Read length } \\
\text { (bp) }\end{array}$ & $\begin{array}{l}\text { Reads generated } \\
\text { per run }\end{array}$ & Accurac \\
\hline 454-Roche & Pyrosequencing & $700-1000$ & 1 million & $99.9 \%$ \\
\hline Illumina & $\begin{array}{l}\text { Sequencing by } \\
\text { synthesis (SBS) }\end{array}$ & $75-300$ & $\begin{array}{l}\text { From } 1 \text { million to } 3 \\
\text { billion, depending } \\
\text { upon the sequencer } \\
\text { model }\end{array}$ & $99.9 \%$ \\
\hline $\begin{array}{l}\text { ABI } \\
\text { SOLiD }\end{array}$ & $\begin{array}{l}\text { Sequencing by } \\
\text { ligation }\end{array}$ & 35-85 & 1.2-1.4 million & $99.9 \%$ \\
\hline $\begin{array}{l}\text { Pacific } \\
\text { biosciences }\end{array}$ & $\begin{array}{l}\text { Single- } \\
\text { molecule } \\
\text { real-time } \\
\text { sequencing }\end{array}$ & $10,000-15,000$ & 500-1000 megabases & $87 \%$ \\
\hline Ion torrent & $\begin{array}{l}\text { Ion } \\
\text { semiconductor }\end{array}$ & up to 400 & 70-80 million & $98 \%$ \\
\hline $\begin{array}{l}\text { Sanger } \\
\text { sequencing }\end{array}$ & $\begin{array}{l}\text { Chain } \\
\text { termination }\end{array}$ & $400-900$ & - & $99.9 \%$ \\
\hline
\end{tabular}




\begin{tabular}{|l|l|l|l|l|}
$\begin{array}{l}\text { NGS } \\
\text { platform }\end{array}$ & Chemistry & $\begin{array}{l}\text { Read length } \\
\text { (bp) }\end{array}$ & $\begin{array}{l}\text { Reads generated } \\
\text { per run }\end{array}$ & Accurac
\end{tabular}

\section{Table 3}

Summary of NGS-based nuclear genome studies in medicinal plants

\begin{tabular}{|c|c|c|c|c|}
\hline $\begin{array}{l}\text { Medicinal } \\
\text { plant }\end{array}$ & $\begin{array}{l}\text { Traditional medicine } \\
\text { uses }\end{array}$ & $\begin{array}{l}\text { NGS } \\
\text { platform }\end{array}$ & Aim & $\begin{array}{l}\text { Geno] } \\
\text { size }\end{array}$ \\
\hline $\begin{array}{l}\text { Azadirachta } \\
\text { indica }\end{array}$ & $\begin{array}{l}\text { Anthelmintic, antifungal, } \\
\text { antidiabetic, antibacterial, } \\
\text { antiviral, contraceptive } \\
\text { and sedative }\end{array}$ & $\begin{array}{l}\text { Illumina; } \\
\text { pacific } \\
\text { biosciences } \\
\text { SMRT }\end{array}$ & $\begin{array}{l}\text { Terpenoid } \\
\text { biosynthesis } \\
\text { pathway }\end{array}$ & $364 \mathrm{~N}$ \\
\hline $\begin{array}{l}\text { Cannabis } \\
\text { sativa }\end{array}$ & $\begin{array}{l}\text { Hallucinogenic, hypnotic, } \\
\text { sedative, analgesic, and } \\
\text { anti-inflammatory }\end{array}$ & $\begin{array}{l}\text { Illumina, } \\
\text { 454-Rosche }\end{array}$ & $\begin{array}{l}\text { Cannabinoid } \\
\text { biosynthesis }\end{array}$ & $534 \mathrm{~N}$ \\
\hline $\begin{array}{l}\text { Capsicum } \\
\text { annuum }\end{array}$ & $\begin{array}{l}\text { Use to treat flatulence, } \\
\text { tympanitis, paralysis, } \\
\text { acute diphtheria, } \\
\text { malignant scarlet fever }\end{array}$ & Illumina & $\begin{array}{l}\text { Evolution, } \\
\text { domestication, } \\
\text { and } \\
\text { specialization } \\
\text { studies }\end{array}$ & $\sim 3.48$ \\
\hline $\begin{array}{l}\text { Dendrobium } \\
\text { catenatum }\end{array}$ & $\begin{array}{l}\text { Anti-Inflammatory, } \\
\text { immuno-enhancing, } \\
\text { antioxidant and } \\
\text { anti-glycation activities }\end{array}$ & Illumina & $\begin{array}{l}\text { Polysaccharide } \\
\text { synthase, } \\
\text { flower } \\
\text { development } \\
\text { and evolution } \\
\text { studies }\end{array}$ & $1.01 \mathrm{C}$ \\
\hline $\begin{array}{l}\text { Elaeis } \\
\text { guineensis }\end{array}$ & $\begin{array}{l}\text { Used as laxative and } \\
\text { diuretic, poison antidote, } \\
\text { cure for gonorrhea, } \\
\text { menorrhagia, bronchitis, } \\
\text { headaches, rheumatism, } \\
\text { healing of fresh wounds } \\
\text { and treat skin infections }\end{array}$ & Illumina & $\begin{array}{l}\text { Oil } \\
\text { biosynthesis } \\
\text { genes }\end{array}$ & 1.535 \\
\hline $\begin{array}{l}\text { Juglans } \\
\text { regia }\end{array}$ & $\begin{array}{l}\text { Antioxidant and } \\
\text { antiproliferative, used to } \\
\text { treat diabetes mellitus }\end{array}$ & Ilumina & $\begin{array}{l}\text { Genes coding } \\
\text { for the } \\
\text { biosynthesis of }\end{array}$ & $667 \mathrm{~N}$ \\
\hline
\end{tabular}




\begin{tabular}{|c|c|c|c|c|}
\hline $\begin{array}{l}\text { Medicinal } \\
\text { plant }\end{array}$ & $\begin{array}{l}\text { Traditional medicine } \\
\text { uses }\end{array}$ & $\begin{array}{l}\text { NGS } \\
\text { platform }\end{array}$ & Aim & $\begin{array}{l}\text { Genol } \\
\text { size }\end{array}$ \\
\hline & symptoms & & $\begin{array}{l}\text { non-structural } \\
\text { polyphenols }\end{array}$ & \\
\hline $\begin{array}{l}\text { Nelumba } \\
\text { nucifera }\end{array}$ & $\begin{array}{l}\text { Anticancer, } \\
\text { antidepressant, cure } \\
\text { insomnia, and diarrhea }\end{array}$ & $\begin{array}{l}\text { Illumina, } \\
\text { 454-Roche }\end{array}$ & $\begin{array}{l}\text { Genome } \\
\text { characterization } \\
\text { and evolution }\end{array}$ & $929 \mathrm{~N}$ \\
\hline $\begin{array}{l}\text { Ocimum } \\
\text { tenuiflorum }\end{array}$ & $\begin{array}{l}\text { Antibacterial, antiallergic, } \\
\text { antidepressant }\end{array}$ & Illumina & $\begin{array}{l}\text { Genes behind } \\
\text { strong } \\
\text { medicinal } \\
\text { properties }\end{array}$ & $374 \mathrm{~N}$ \\
\hline $\begin{array}{l}\text { Prunus } \\
\text { mume }\end{array}$ & $\begin{array}{l}\text { Antimicrobial, prevent } \\
\text { gastritis and gastric } \\
\text { ulcers, enhance the } \\
\text { oxidative capacity }\end{array}$ & Illumina & $\begin{array}{l}\text { Genome } \\
\text { characterization } \\
\text { and evolution }\end{array}$ & $280 \mathrm{~N}$ \\
\hline $\begin{array}{l}\text { Pyrus } \\
\text { communis }\end{array}$ & Antimicrobial, antiseptic & 454-Roche & $\begin{array}{l}\text { Genome } \\
\text { characterization }\end{array}$ & $577 \mathrm{~N}$ \\
\hline $\begin{array}{l}\text { Ziziphus } \\
\text { jujuba }\end{array}$ & $\begin{array}{l}\text { Alleviate stress, } \\
\text { anti-fungal, anti-bacterial, } \\
\text { anti-ulcer, } \\
\text { anti-inflammatory, } \\
\text { antispastic, } \\
\text { antifertility/contraception, } \\
\text { hypotensive and } \\
\text { antinephritic, cardiotonic, } \\
\text { antioxidant, } \\
\text { immunostimulant, and } \\
\text { wound healing properties }\end{array}$ & Illumina & $\begin{array}{l}\text { Vitamin C } \\
\text { content, } \\
\text { genomic } \\
\text { resource }\end{array}$ & $437.6 !$ \\
\hline
\end{tabular}

\section{Table 4}

NGS-based transcriptome studies on medicinal plants

\begin{tabular}{|l|l|l|l|}
\hline $\begin{array}{l}\text { Medicinal } \\
\text { plant }\end{array}$ & $\begin{array}{l}\text { Therapeutic } \\
\text { potential }\end{array}$ & Aim of study & References \\
\hline Allium sativum & $\begin{array}{l}\text { Antimicrobial, } \\
\text { antithrombotic, } \\
\text { hypolipidemic, } \\
\text { antiarthritic, } \\
\text { hypoglycemic and } \\
\text { antitumor activity }\end{array}$ & $\begin{array}{l}\text { De novo assembly } \\
\text { and } \\
\text { characterization } \\
\text { of transcriptome; } \\
\text { genes involved in } \\
\text { biosynthesis of } \\
\text { organic sulfur }\end{array}$ & $\begin{array}{l}\text { Sun et al. } \\
\text { (2012a, b ) }\end{array}$ \\
\hline
\end{tabular}




\begin{tabular}{|c|c|c|c|}
\hline $\begin{array}{l}\text { Medicinal } \\
\text { plant }\end{array}$ & $\begin{array}{l}\text { Therapeutic } \\
\text { potential }\end{array}$ & Aim of study & References \\
\hline $\begin{array}{l}\text { Amorphophallus } \\
\text { konjac; } \\
\text { Amorphophallus } \\
\text { bulbifer }\end{array}$ & $\begin{array}{l}\text { Treatment of asthma, } \\
\text { cough, hernia, breast } \\
\text { pain, burns as well as } \\
\text { hematological and } \\
\text { skin disorders }\end{array}$ & $\begin{array}{l}\text { development of } \\
\text { transcriptome data } \\
\text { and microsatellite } \\
\text { markers }\end{array}$ & $\begin{array}{l}\text { Zheng et al. } \\
\text { (2013) }\end{array}$ \\
\hline $\begin{array}{l}\text { Andrographis } \\
\text { paniculata }\end{array}$ & $\begin{array}{l}\text { Used in treatment of } \\
\text { cancer, diabetes, high } \\
\text { blood pressure, ulcer, } \\
\text { leprosy, bronchitis, } \\
\text { skin diseases, } \\
\text { flatulence, colic, } \\
\text { influenza, dysentery, } \\
\text { dyspepsia and malaria }\end{array}$ & $\begin{array}{l}\text { Identification of } \\
\text { novel genes for } \\
\text { Ent-labdane- } \\
\text { related diterpene } \\
\text { (ent-LRD) } \\
\text { biosynthetic } \\
\text { pathway }\end{array}$ & $\begin{array}{l}\text { Garg et al. } \\
\text { (2015) }\end{array}$ \\
\hline $\begin{array}{l}\text { Asparagus } \\
\text { racemosus }\end{array}$ & $\begin{array}{l}\text { Used as a uterine } \\
\text { tonic, to improve } \\
\text { breast milk, in } \\
\text { hyperacidity, and as a } \\
\text { general health tonic }\end{array}$ & $\begin{array}{l}\text { Identification of } \\
\text { novel genes } \\
\text { involved in } \\
\text { steroidal } \\
\text { sapogenin } \\
\text { biosynthesis }\end{array}$ & $\begin{array}{l}\text { Upadhyay et } \\
\text { al. (2014) }\end{array}$ \\
\hline $\begin{array}{l}\text { Astragalus } \\
\text { chrysochlorus }\end{array}$ & $\begin{array}{l}\text { Act as adaptogen, } \\
\text { treatment of anemia, } \\
\text { cold, influenza, } \\
\text { diabetes, fatigue or } \\
\text { lack of appetite from } \\
\text { chemotherapy, heart } \\
\text { diseases, hepatitis, } \\
\text { kidney disease }\end{array}$ & $\begin{array}{l}\text { Transcriptome } \\
\text { profiling; to study } \\
\text { selenium } \\
\text { accumulation and } \\
\text { tolerance } \\
\text { mechanisms }\end{array}$ & $\begin{array}{l}\text { Cakir et al. } \\
\text { (2015) }\end{array}$ \\
\hline $\begin{array}{l}\text { Astragalus } \\
\text { membranaceus }\end{array}$ & $\begin{array}{l}\text { Used to treat common } \\
\text { cold, respiratory } \\
\text { infections, allergies, } \\
\text { fibromyalgia, anemia, } \\
\text { HIV/AIDS, and to } \\
\text { strengthen immunity }\end{array}$ & $\begin{array}{l}\text { Characterization } \\
\text { of transcriptome }\end{array}$ & $\begin{array}{l}\text { Liu et al. } \\
(2014 a, b)\end{array}$ \\
\hline $\begin{array}{l}\text { Atractylodes } \\
\text { lancea }\end{array}$ & $\begin{array}{l}\text { Anticancer, } \\
\text { anti-inflammatory, } \\
\text { antimicrobial, } \\
\text { antipyretic, and } \\
\text { activities on central } \\
\text { nervous, } \\
\text { cardiovascular, and } \\
\text { gastrointestinal } \\
\text { systems }\end{array}$ & $\begin{array}{l}\text { gene } \\
\text { identification } \\
\text { involved in } \\
\text { sesquiterpenoid } \\
\text { biosynthesis }\end{array}$ & $\begin{array}{l}\text { Ahmed et al. } \\
\text { (2016) }\end{array}$ \\
\hline
\end{tabular}




\begin{tabular}{|c|c|c|c|}
\hline $\begin{array}{l}\text { Medicinal } \\
\text { plant }\end{array}$ & $\begin{array}{l}\text { Therapeutic } \\
\text { potential }\end{array}$ & Aim of study & References \\
\hline $\begin{array}{l}\text { Azadirachta } \\
\text { indica }\end{array}$ & $\begin{array}{l}\text { Anthelmintic, } \\
\text { antifungal, antidibitic, } \\
\text { antibacterial, } \\
\text { antiviral, } \\
\text { contraceptive, } \\
\text { sedative }\end{array}$ & $\begin{array}{l}\text { Characterization } \\
\text { of metabolic } \\
\text { pathways } \\
\text { involved in } \\
\text { synthesis of } \\
\text { bioactive } \\
\text { compounds; } \\
\text { comparative } \\
\text { evolutionary } \\
\text { studies and } \\
\text { understanding of } \\
\text { molecular } \\
\text { pathways } \\
\text { involved in the } \\
\text { azadirachtin } \\
\text { synthesis }\end{array}$ & $\begin{array}{l}\text { Krishnan et al. } \\
\text { (2012) }\end{array}$ \\
\hline $\begin{array}{l}\text { Calotropis } \\
\text { gigantea }\end{array}$ & $\begin{array}{l}\text { Used for digestive } \\
\text { disorders including } \\
\text { diarrhea, constipation } \\
\text { and stomach ulcers }\end{array}$ & $\begin{array}{l}\text { Transcriptome } \\
\text { study; } \\
\text { identification of } \\
\text { genes in } \\
\text { secondary } \\
\text { metabolites } \\
\text { biosynthesis }\end{array}$ & $\begin{array}{l}\text { Muriira et al. } \\
\text { (2015) }\end{array}$ \\
\hline $\begin{array}{l}\text { Carthamus } \\
\text { tinctorius }\end{array}$ & $\begin{array}{l}\text { Used to treat } \\
\text { dysmenorrhea, } \\
\text { amenorrhea, } \\
\text { postpartum abdominal } \\
\text { pain and mass, trauma } \\
\text { and pain of joints }\end{array}$ & $\begin{array}{l}\text { De novo } \\
\text { transcriptome } \\
\text { assembly }\end{array}$ & $\begin{array}{l}\text { Lulin et al. } \\
\text { (2012) }\end{array}$ \\
\hline $\begin{array}{l}\text { Cassia } \\
\text { angustifolia }\end{array}$ & $\begin{array}{l}\text { Treatment of } \\
\text { constipation, irritable } \\
\text { bowel syndrome, } \\
\text { hemorrhoids, and } \\
\text { weight loss }\end{array}$ & $\begin{array}{l}\text { Identification of } \\
\text { genes involved in } \\
\text { various secondary } \\
\text { metabolite } \\
\text { pathways; } \\
\text { especially those } \\
\text { related to the } \\
\text { synthesis of } \\
\text { sennosides }\end{array}$ & $\begin{array}{l}\text { Reddy et al. } \\
\text { (2015) }\end{array}$ \\
\hline Catha edulis & $\begin{array}{l}\text { To treat obesity, } \\
\text { dysphoria and } \\
\text { sedation }\end{array}$ & $\begin{array}{l}\text { Identification of } \\
\text { gene candidates } \\
\text { potentially } \\
\text { involved in } \\
\text { amphetamine-type } \\
\text { alkaloid }\end{array}$ & $\begin{array}{l}\text { Groves et al. } \\
\text { (2015) }\end{array}$ \\
\hline
\end{tabular}




\begin{tabular}{|c|c|c|c|}
\hline $\begin{array}{l}\text { Medicinal } \\
\text { plant }\end{array}$ & $\begin{array}{l}\text { Therapeutic } \\
\text { potential }\end{array}$ & Aim of study & References \\
\hline & & biosynthesis & \\
\hline $\begin{array}{l}\text { Catharanthus } \\
\text { roseus }\end{array}$ & $\begin{array}{l}\text { Lowers blood } \\
\text { pressure, } \\
\text { anti-diabetic, } \\
\text { anticancer, antiviral, } \\
\text { antibacterial }\end{array}$ & $\begin{array}{l}\text { Development of } \\
\text { CathaCyc, a } \\
\text { metabolic } \\
\text { pathway database }\end{array}$ & $\begin{array}{l}\text { Van } \\
\text { Moerkercke et } \\
\text { al. (2013) }\end{array}$ \\
\hline $\begin{array}{l}\text { Centella } \\
\text { asiatica }\end{array}$ & $\begin{array}{l}\text { Treatment of varicos } \\
\text { veins, psoriasis, } \\
\text { chronic venus } \\
\text { insufficiency, minor } \\
\text { wounds }\end{array}$ & $\begin{array}{l}\text { Identification of } \\
\text { genes of terpenoid } \\
\text { and ROS } \\
\text { metabolism; } \\
\text { mining out } \\
\text { secondary- } \\
\text { metabolism genes; } \\
\text { discovery of novel } \\
\text { genes for } \\
\text { biosynthetic } \\
\text { pathways }\end{array}$ & $\begin{array}{l}\text { Sangwan et al. } \\
\text { (2013) }\end{array}$ \\
\hline $\begin{array}{l}\text { Chlorophytum } \\
\text { borivilianum }\end{array}$ & Used as adaptogen & $\begin{array}{l}\text { Study of } \\
\text { molecular } \\
\text { network and } \\
\text { important } \\
\text { pathways }\end{array}$ & $\begin{array}{l}\text { Kalra et al. } \\
(2013)\end{array}$ \\
\hline $\begin{array}{l}\text { Codonopsis } \\
\text { pilosula }\end{array}$ & $\begin{array}{l}\text { To improve appetite } \\
\text { and energy }\end{array}$ & $\begin{array}{l}\text { Elucidation of } \\
\text { genes involved in } \\
\text { biosynthetic } \\
\text { pathways for } \\
\text { codonopsis } \\
\text { polysaccharides }\end{array}$ & $\begin{array}{l}\text { Gao et al. } \\
\text { (2015) }\end{array}$ \\
\hline Curcuma longa & $\begin{array}{l}\text { Used to treat a variety } \\
\text { of internal disorders, } \\
\text { such as indigestion, } \\
\text { throat infections, } \\
\text { common colds, or } \\
\text { liver ailments, as well } \\
\text { as topically to cleanse } \\
\text { wounds or treat skin } \\
\text { sores }\end{array}$ & $\begin{array}{l}\text { De novo } \\
\text { transcriptome } \\
\text { assembly; } \\
\text { identification of } \\
\text { novel transcripts } \\
\text { related to } \\
\text { anticancer and } \\
\text { antimalarial } \\
\text { terpenoids }\end{array}$ & $\begin{array}{l}\text { Annadurai et } \\
\text { al. (2013) }\end{array}$ \\
\hline $\begin{array}{l}\text { Cymbopogon } \\
\text { flexuosus }\end{array}$ & $\begin{array}{l}\text { Treatment of } \\
\text { digestive tract } \\
\text { spasms, stomachache, } \\
\text { high blood pressure, } \\
\text { convulsions, pain, }\end{array}$ & $\begin{array}{l}\text { De novo } \\
\text { transcriptome } \\
\text { assembly; } \\
\text { identification of } \\
\text { genes involved in }\end{array}$ & $\begin{array}{l}\text { Meena et al. } \\
\text { (2016) }\end{array}$ \\
\hline
\end{tabular}




\begin{tabular}{|c|c|c|c|}
\hline $\begin{array}{l}\text { Medicinal } \\
\text { plant }\end{array}$ & $\begin{array}{l}\text { Therapeutic } \\
\text { potential }\end{array}$ & Aim of study & References \\
\hline & $\begin{array}{l}\text { vomiting, cough, achy } \\
\text { joints (rheumatism), } \\
\text { fever, the common } \\
\text { cold, and exhaustion }\end{array}$ & essential oils & \\
\hline $\begin{array}{l}\text { Dendrobium } \\
\text { officinale }\end{array}$ & $\begin{array}{l}\text { Tonic for longevity, } \\
\text { used to boost physical } \\
\text { and athletic } \\
\text { performance }\end{array}$ & $\begin{array}{l}\text { Identification of } \\
\text { alkaloid } \\
\text { biosynthesis } \\
\text { genes; genetic } \\
\text { markers } \\
\text { development }\end{array}$ & $\begin{array}{l}\text { Guo et al. } \\
\text { (2013) }\end{array}$ \\
\hline $\begin{array}{l}\text { Digitalis } \\
\text { purpurea }\end{array}$ & $\begin{array}{l}\text { Used for congestive } \\
\text { heart failure, } \\
\text { relieving associated } \\
\text { fluid retention } \\
\text { (edema), irregular } \\
\text { heartbeats, asthma, } \\
\text { epilepsy, tuberculosis, } \\
\text { constipation, and } \\
\text { headache }\end{array}$ & $\begin{array}{l}\text { study of } \\
\text { comparative } \\
\text { analysis of } \\
\text { alternate splicing }\end{array}$ & $\begin{array}{l}\text { Wu et al. } \\
\text { (2014) }\end{array}$ \\
\hline $\begin{array}{l}\text { Eleutherococcus } \\
\text { senticosus }\end{array}$ & $\begin{array}{l}\text { To treat bone marrow } \\
\text { suppression angina, } \\
\text { hypercholesterolemia, } \\
\text { and neurasthenia with } \\
\text { headache, insomnia, } \\
\text { and poor appetite }\end{array}$ & $\begin{array}{l}\text { Transcriptome } \\
\text { profiling; } \\
\text { identification of } \\
\text { genes involved in } \\
\text { somatic } \\
\text { embryogenesis }\end{array}$ & $\begin{array}{l}\text { Tao et al. } \\
\text { (2016) }\end{array}$ \\
\hline Ephedra sinica & $\begin{array}{l}\text { Treat symptoms of } \\
\text { bronchial asthma, } \\
\text { colds, influenza, } \\
\text { allergies, and hives in } \\
\text { teas or tinctures }\end{array}$ & $\begin{array}{l}\text { De novo } \\
\text { transcriptome } \\
\text { assembly; } \\
\text { comparative } \\
\text { transcriptome } \\
\text { analysis for aerial } \\
\text { roots and stems }\end{array}$ & $\begin{array}{l}\text { Groves et al. } \\
\text { (2015) }\end{array}$ \\
\hline $\begin{array}{l}\text { Erigeron } \\
\text { breviscapus }\end{array}$ & $\begin{array}{l}\text { Treatment of } \\
\text { cerebrovascular } \\
\text { diseases }\end{array}$ & $\begin{array}{l}\text { Generation of } \\
\text { transcriptome } \\
\text { sequence } \\
\text { resource; effect of } \\
\text { methyl jasmonate } \\
\text { (MeJA) on } \\
\text { scutellarin } \\
\text { biosynthesis }\end{array}$ & $\begin{array}{l}\text { Chen et al. } \\
\text { (2015) }\end{array}$ \\
\hline $\begin{array}{l}\text { Gentiana } \\
\text { macrophylla }\end{array}$ & $\begin{array}{l}\text { Used in treatment of } \\
\text { jaundice, hepatitis, }\end{array}$ & $\begin{array}{l}\text { Identification of } \\
\text { genes involved in }\end{array}$ & $\begin{array}{l}\text { Hua et al. } \\
\text { (2014) }\end{array}$ \\
\hline
\end{tabular}




\begin{tabular}{|c|c|c|c|}
\hline $\begin{array}{l}\text { Medicinal } \\
\text { plant }\end{array}$ & $\begin{array}{l}\text { Therapeutic } \\
\text { potential }\end{array}$ & Aim of study & References \\
\hline & $\begin{array}{l}\text { and stomachic and } \\
\text { choleretic ailments }\end{array}$ & $\begin{array}{l}\text { secoiridoid } \\
\text { biosynthesis }\end{array}$ & \\
\hline $\begin{array}{l}\text { Gentiana } \\
\text { rigescens }\end{array}$ & $\begin{array}{l}\text { Treatment of fever, } \\
\text { hypertension, muscle } \\
\text { spasms, parasitic } \\
\text { worms, wounds, } \\
\text { cancer, sinusitis, and } \\
\text { malaria }\end{array}$ & $\begin{array}{l}\text { De novo } \\
\text { transcriptome } \\
\text { assembly; } \\
\text { identification of } \\
\text { genes involved in } \\
\text { terpenoid } \\
\text { biosynthesis }\end{array}$ & $\begin{array}{l}\text { Zhang et al. } \\
\text { (2015a, b) }\end{array}$ \\
\hline $\begin{array}{l}\text { Glycyrrhiza } \\
\text { uralensis }\end{array}$ & $\begin{array}{l}\text { Treatment of } \\
\text { arrhythmia, ulcers, } \\
\text { inhibits gastric acid } \\
\text { secretion, relieves } \\
\text { gastrointestinal } \\
\text { smooth muscle } \\
\text { spasm, eases pain, } \\
\text { promotes the } \\
\text { secretion of } \\
\text { pancreatic juice, } \\
\text { relieves cough } \\
\text { significantly, prevents } \\
\text { asthma, antibacterial, } \\
\text { antiviral, } \\
\text { anti-inflammatory, } \\
\text { anti-allergic }\end{array}$ & $\begin{array}{l}\text { Elucidation of } \\
\text { biosynthetic } \\
\text { pathways of } \\
\text { secondary } \\
\text { metabolites }\end{array}$ & $\begin{array}{l}\text { Ramilowski et } \\
\text { al. (2013) }\end{array}$ \\
\hline Helwingia willd & $\begin{array}{l}\text { Antibacterial, } \\
\text { anti-inflammatory and } \\
\text { blood lipid reducing } \\
\text { effects }\end{array}$ & $\begin{array}{l}\text { Transcriptomic } \\
\text { exploration and } \\
\text { phylogenetic } \\
\text { analysis }\end{array}$ & $\begin{array}{l}\text { Sun et al. } \\
(2014)\end{array}$ \\
\hline $\begin{array}{l}\text { Hypericum } \\
\text { perforatum }\end{array}$ & $\begin{array}{l}\text { Antidepressant and } \\
\text { anticancer activities }\end{array}$ & $\begin{array}{l}\text { Identification of } \\
\text { potential genes } \\
\text { that are related to } \\
\text { plant reproduction }\end{array}$ & $\begin{array}{l}\text { Galla et al. } \\
\text { (2015) }\end{array}$ \\
\hline $\begin{array}{l}\text { Hypericum } \\
\text { perforatum }\end{array}$ & $\begin{array}{l}\text { Antidepressent, } \\
\text { anti-inflamatery }\end{array}$ & $\begin{array}{l}\text { Identification of } \\
\text { potential genes } \\
\text { involved in the } \\
\text { biosynthesis of } \\
\text { active metabolites }\end{array}$ & $\begin{array}{l}\text { He et al. } \\
\text { (2012) }\end{array}$ \\
\hline $\begin{array}{l}\text { Lonicera } \\
\text { japonica }\end{array}$ & $\begin{array}{l}\text { Used to treat fever, } \\
\text { headache, cough, } \\
\text { thirst and sore throat }\end{array}$ & $\begin{array}{l}\text { De novo } \\
\text { transcriptome } \\
\text { assembly; identify } \\
\text { genes involved in }\end{array}$ & $\begin{array}{l}\text { Yuan et al. } \\
\text { (2012); Rai et } \\
\text { al. (2016) }\end{array}$ \\
\hline
\end{tabular}




\begin{tabular}{|c|c|c|c|}
\hline $\begin{array}{l}\text { Medicinal } \\
\text { plant }\end{array}$ & $\begin{array}{l}\text { Therapeutic } \\
\text { potential }\end{array}$ & Aim of study & References \\
\hline & & $\begin{array}{l}\text { chlorogenic acid, } \\
\text { luteolosides, and } \\
\text { secoiridoid } \\
\text { biosynthesis } \\
\text { pathways }\end{array}$ & \\
\hline $\begin{array}{l}\text { Lotus } \\
\text { corniculatus }\end{array}$ & $\begin{array}{l}\text { Antiinflammatory, } \\
\text { antispasmodic, } \\
\text { cardiotonic, } \\
\text { carminative, } \\
\text { febrifuge, } \\
\text { hypoglycaemic, } \\
\text { restorative, sedative, } \\
\text { tonic, vermifuge }\end{array}$ & $\begin{array}{l}\text { Identification of } \\
\text { genes for key } \\
\text { enzymes and } \\
\text { potential } \\
\text { transcription } \\
\text { factors related to } \\
\text { the flavonoid } \\
\text { biosynthesis } \\
\text { pathway }\end{array}$ & $\begin{array}{l}\text { Wang et al. } \\
\text { (2013) }\end{array}$ \\
\hline Lycium chinense & $\begin{array}{l}\text { Supplementing the } \\
\text { kidney and liver, } \\
\text { benefiting the eyes, } \\
\text { enhancing immune } \\
\text { functions, and } \\
\text { protecting against } \\
\text { adverse impact of } \\
\text { oxidation }\end{array}$ & $\begin{array}{l}\text { Identification of } \\
\text { phenylpropanoid } \\
\text { biosynthetic genes } \\
\text { and } \\
\text { phenylpropanoid } \\
\text { accumulation; de } \\
\text { novo } \\
\text { transcriptome } \\
\text { assembly; } \\
\text { essential genes } \\
\text { involved in the } \\
\text { carotenoid } \\
\text { biosynthesis } \\
\text { pathway }\end{array}$ & $\begin{array}{l}\text { Zhao et al. } \\
\text { ( } 2013 \text { ); Wang } \\
\text { et al. (2015a, } \\
\text { b) }\end{array}$ \\
\hline $\begin{array}{l}\text { Magnolia } \\
\text { sprengeri }\end{array}$ & $\begin{array}{l}\text { To treat menstrual } \\
\text { cramps, abdominal } \\
\text { pain, abdominal } \\
\text { bloating and gas, } \\
\text { nausea, and } \\
\text { indigestion }\end{array}$ & $\begin{array}{l}\text { Identification of } \\
\text { structural and } \\
\text { regulatory genes } \\
\text { encoding the } \\
\text { enzymes involved } \\
\text { in the } \\
\text { determination of } \\
\text { flower color }\end{array}$ & $\begin{array}{l}\text { Shi et al. } \\
\text { (2014) }\end{array}$ \\
\hline Ocimum sp. & $\begin{array}{l}\text { Anti inflammatory, } \\
\text { effective in skin } \\
\text { rashes, insect bites } \\
\text { and itching, effective } \\
\text { in fever, cough, } \\
\text { bronchitis, acts as a } \\
\text { cardiac tonic and } \\
\text { purifies blood, very }\end{array}$ & $\begin{array}{l}\text { De novo } \\
\text { transcriptome } \\
\text { assembly; } \\
\text { comparative } \\
\text { analysis }\end{array}$ & $\begin{array}{l}\text { Rastogi et al. } \\
\text { (2014) }\end{array}$ \\
\hline
\end{tabular}




\begin{tabular}{|c|c|c|c|}
\hline $\begin{array}{l}\text { Medicinal } \\
\text { plant }\end{array}$ & $\begin{array}{l}\text { Therapeutic } \\
\text { potential }\end{array}$ & Aim of study & References \\
\hline & $\begin{array}{l}\text { effective in reducing } \\
\text { blood sugar and blood } \\
\text { cholesterol }\end{array}$ & & \\
\hline Panax ginseng & $\begin{array}{l}\text { Used in treatment for } \\
\text { Alzheimer's disease, } \\
\text { lung disease, flu, } \\
\text { erectile dysfunction, } \\
\text { multiple sclerosis- } \\
\text { related fatigue, } \\
\text { improves mental } \\
\text { function }\end{array}$ & $\begin{array}{l}\text { Identification of } \\
\text { novel and } \\
\text { conserved } \\
\text { miRNAs; } \\
\text { development of } \\
\text { root } \\
\text { transcriptome; } \\
\text { genes for } \\
\text { secondary } \\
\text { metabolites } \\
\text { biosynthesis }\end{array}$ & $\begin{array}{l}\text { Wu et al. } \\
\text { ( } 2012) ; \mathrm{Li} \text { et } \\
\text { al. (2013); } \\
\text { Jayakodi et al. } \\
\text { (2015); } \\
\text { Subramaniyam } \\
\text { et al. (2014) }\end{array}$ \\
\hline $\begin{array}{l}\text { Panax } \\
\text { japonicus }\end{array}$ & $\begin{array}{l}\text { Used as a tonic, } \\
\text { anti-inflammatory and } \\
\text { haemostatic agent }\end{array}$ & $\begin{array}{l}\text { Generation of } \\
\text { transcriptome } \\
\text { data; } \\
\text { identification of } \\
\text { genes involved in } \\
\text { triterpenoid } \\
\text { saponin backbone } \\
\text { biosynthesis }\end{array}$ & $\begin{array}{l}\text { Zhang et al. } \\
\text { (2015) }\end{array}$ \\
\hline $\begin{array}{l}\text { Panax } \\
\text { notoginseng }\end{array}$ & $\begin{array}{l}\text { Lower cholesterol; } \\
\text { improves } \\
\text { cardiovascular } \\
\text { function }\end{array}$ & $\begin{array}{l}\text { Establishment of } \\
\text { global } \\
\text { transcriptome } \\
\text { dataset; candidate } \\
\text { genes involved in } \\
\text { ginsenoside and } \\
\text { alkaloid } \\
\text { biosynthesis }\end{array}$ & $\begin{array}{l}\text { Liu et al. } \\
(2015 a, b)\end{array}$ \\
\hline $\begin{array}{l}\text { Panax } \\
\text { quinquefolius }\end{array}$ & $\begin{array}{l}\text { Improves } \\
\text { neurocognitive } \\
\text { function, memory }\end{array}$ & $\begin{array}{l}\text { Identification of } \\
\text { insenoside } \\
\text { biosynthesis } \\
\text { genes; to provide } \\
\text { transcriptome } \\
\text { sequences for } \\
\text { seed dormancy }\end{array}$ & $\begin{array}{l}\text { Wu et al. } \\
\text { (2013); Qi et } \\
\text { al. (2015) }\end{array}$ \\
\hline $\begin{array}{l}\text { Panax } \\
\text { vietnamensis }\end{array}$ & $\begin{array}{l}\text { protect stress-induced } \\
\text { antinociception, } \\
\text { gastric lesions, } \\
\text { pentobarbital sleep }\end{array}$ & $\begin{array}{l}\text { Identification of } \\
\text { putative genes } \\
\text { involved in } \\
\text { triterpenoid } \\
\text { saponins } \\
\text { biosynthesis }\end{array}$ & $\begin{array}{l}\text { Zhang et al. } \\
\text { (2015) }\end{array}$ \\
\hline
\end{tabular}




\begin{tabular}{|c|c|c|c|}
\hline $\begin{array}{l}\text { Medicinal } \\
\text { plant }\end{array}$ & $\begin{array}{l}\text { Therapeutic } \\
\text { potential }\end{array}$ & Aim of study & References \\
\hline & & $\begin{array}{l}\text { pathway; SSR } \\
\text { markers } \\
\text { development }\end{array}$ & \\
\hline $\begin{array}{l}\text { Paphiopedilum } \\
\text { concolor }\end{array}$ & $\begin{array}{l}\text { Treatment to reduce } \\
\text { inflammation and } \\
\text { acesodyne, } \\
\text { dysmenorrheal, colic, } \\
\text { and cystitis }\end{array}$ & $\begin{array}{l}\text { De novo } \\
\text { transcriptome } \\
\text { assembly; } \\
\text { development of } \\
\text { microsatellite } \\
\text { markers }\end{array}$ & $\begin{array}{l}\text { Li et al. } \\
\text { (2015) }\end{array}$ \\
\hline $\begin{array}{l}\text { Phyllanthus } \\
\text { amarus }\end{array}$ & $\begin{array}{l}\text { Use to treat bladder } \\
\text { infections, colds, } \\
\text { diabetes, hepatitis B, } \\
\text { kidney disorders, } \\
\text { ulcers, urinary tract } \\
\text { infections }\end{array}$ & $\begin{array}{l}\text { De novo } \\
\text { transcriptome } \\
\text { assembly; } \\
\text { decipher various } \\
\text { secondary } \\
\text { metabolite } \\
\text { pathways }\end{array}$ & $\begin{array}{l}\text { Mazumdar and } \\
\text { Chattopadhyay } \\
\text { (2015) }\end{array}$ \\
\hline $\begin{array}{l}\text { Picrorhiza } \\
\text { kurroa }\end{array}$ & $\begin{array}{l}\text { Treatment of } \\
\text { digestive problems, } \\
\text { asthma, liver damage, } \\
\text { wound healing, } \\
\text { vitiligo }\end{array}$ & $\begin{array}{l}\text { De novo } \\
\text { transcriptome } \\
\text { assembly; } \\
\text { identification of } \\
\text { genes involved in } \\
\text { picrosides } \\
\text { biosynthesis }\end{array}$ & $\begin{array}{l}\text { Gahlan et al. } \\
\text { (2012) }\end{array}$ \\
\hline Pinellia ternata & $\begin{array}{l}\text { Removing dampness- } \\
\text { phlegm, thermo- } \\
\text { genesis, treatment of } \\
\text { flu }\end{array}$ & $\begin{array}{l}\text { Comprehensive } \\
\text { transcriptome } \\
\text { analysis; } \\
\text { identification of } \\
\text { genes involved in } \\
\text { the biosynthesis } \\
\text { of benzoic acid } \\
\text { and ephedrine }\end{array}$ & $\begin{array}{l}\text { Huang et al. } \\
\text { (2016); Zhnag } \\
\text { et al. (2016a, } \\
\text { b) }\end{array}$ \\
\hline Plantago ovata & $\begin{array}{l}\text { Used to improve } \\
\text { gastrointestinal } \\
\text { functions, weight } \\
\text { loss, prevention and } \\
\text { treatment of } \\
\text { hypertension and } \\
\text { heart diseases }\end{array}$ & $\begin{array}{l}\text { De novo } \\
\text { transcriptome } \\
\text { assembly; } \\
\text { characterization } \\
\text { of mucilage } \\
\text { biosynthesis } \\
\text { pathway }\end{array}$ & $\begin{array}{l}\text { Kotwal et al. } \\
\text { (2016) }\end{array}$ \\
\hline $\begin{array}{l}\text { Platycodon } \\
\text { grandiflorum }\end{array}$ & $\begin{array}{l}\text { Lung-heat-clearing, } \\
\text { antitussive, } \\
\text { expectorant }\end{array}$ & $\begin{array}{l}\text { Transcriptome } \\
\text { profiling; gene } \\
\text { discovery; marker } \\
\text { development; }\end{array}$ & $\begin{array}{l}\text { Ma et al. } \\
\text { (2016); Kim } \\
\text { et al. (2015) }\end{array}$ \\
\hline
\end{tabular}




\begin{tabular}{|c|c|c|c|}
\hline $\begin{array}{l}\text { Medicinal } \\
\text { plant }\end{array}$ & $\begin{array}{l}\text { Therapeutic } \\
\text { potential }\end{array}$ & Aim of study & References \\
\hline & & $\begin{array}{l}\text { identification of } \\
\text { candidate genes } \\
\text { involved in the } \\
\text { biosynthesis of } \\
\text { triterpenoid } \\
\text { saponins }\end{array}$ & \\
\hline $\begin{array}{l}\text { Polygala } \\
\text { tenuifolia }\end{array}$ & $\begin{array}{l}\text { Used as sedative, } \\
\text { antipsychotic, } \\
\text { cognition improving, } \\
\text { neuroprotective and } \\
\text { antidepressant }\end{array}$ & $\begin{array}{l}\text { Identification of } \\
\text { genes involved in } \\
\text { various secondary } \\
\text { metabolites } \\
\text { biosynthesis } \\
\text { pathways }\end{array}$ & $\begin{array}{l}\text { Tian et al. } \\
\text { (2015) }\end{array}$ \\
\hline $\begin{array}{l}\text { Polygonum } \\
\text { multiflorum }\end{array}$ & $\begin{array}{l}\text { Treatment of liver } \\
\text { injury, cancer, } \\
\text { diabetes, alopecia, } \\
\text { atherosclerosis, and } \\
\text { neurodegenerative } \\
\text { diseases }\end{array}$ & $\begin{array}{l}\text { Study of } \\
\text { mechanisms of } \\
\text { MeJA-mediated } \\
\text { stilbenoid } \\
\text { biosynthesis }\end{array}$ & $\begin{array}{l}\text { Liu et al. } \\
\text { (2016) }\end{array}$ \\
\hline $\begin{array}{l}\text { Polyporus } \\
\text { umbellatus }\end{array}$ & $\begin{array}{l}\text { Immunostimulating, } \\
\text { anticancer, } \\
\text { anti-inflammatory, } \\
\text { and hepatoprotective } \\
\text { properties }\end{array}$ & $\begin{array}{l}\text { Transcriptome } \\
\text { analysis of genes } \\
\text { involved in } \\
\text { defence response } \\
\text { with Armillaria } \\
\text { mellea infection }\end{array}$ & $\begin{array}{l}\text { Liu et al. } \\
(2015 a, b)\end{array}$ \\
\hline $\begin{array}{l}\text { Rehmannia } \\
\text { glutinosa }\end{array}$ & $\begin{array}{l}\text { Treatment of tinnitus, } \\
\text { hair loss, scavenging } \\
\text { of free radicals }\end{array}$ & $\begin{array}{l}\text { Identification of } \\
\text { the genes } \\
\text { responding to } \\
\text { replanting disease }\end{array}$ & $\begin{array}{l}\text { Yang et al. } \\
\text { (2015) }\end{array}$ \\
\hline $\begin{array}{l}\text { Rehmannia } \\
\text { glutinosa }\end{array}$ & $\begin{array}{l}\text { Use to treat diabetes, } \\
\text { anemia, fever, } \\
\text { osteoporesis, allergies }\end{array}$ & $\begin{array}{l}\text { Identification of } \\
\text { genes involved in } \\
\text { iridoid } \\
\text { biosynthesis }\end{array}$ & $\begin{array}{l}\text { Sun et al. } \\
(2012 a, b)\end{array}$ \\
\hline Rhodiola algida & $\begin{array}{l}\text { Treating cancer, } \\
\text { diabetes, tuberculosis, } \\
\text { cold, flu, liver } \\
\text { damage, aging, } \\
\text { improves hearing and } \\
\text { strangthen immunity }\end{array}$ & $\begin{array}{l}\text { Characterization } \\
\text { of important traits } \\
\text { related to } \\
\text { secondary } \\
\text { metabolite } \\
\text { formation } \\
\text { associated } \\
\text { molecular } \\
\text { mechanis ms }\end{array}$ & $\begin{array}{l}\text { Zhang et al. } \\
\text { (2014) }\end{array}$ \\
\hline
\end{tabular}




\begin{tabular}{|c|c|c|c|}
\hline $\begin{array}{l}\text { Medicinal } \\
\text { plant }\end{array}$ & $\begin{array}{l}\text { Therapeutic } \\
\text { potential }\end{array}$ & Aim of study & References \\
\hline $\begin{array}{l}\text { Salvia } \\
\text { miltiorrhiza }\end{array}$ & $\begin{array}{l}\text { Treatment of chronic } \\
\text { renal failure, coronary } \\
\text { heart disease, diabetes }\end{array}$ & $\begin{array}{l}\text { Insight into } \\
\text { tanshinone } \\
\text { biosynthesis; } \\
\text { alternate splicing }\end{array}$ & $\begin{array}{l}\text { Yang et al. } \\
\text { (2013); Xu et } \\
\text { al. (2015) }\end{array}$ \\
\hline $\begin{array}{l}\text { Scutellaria } \\
\text { baicalensis }\end{array}$ & $\begin{array}{l}\text { To treat respiratory } \\
\text { infections, hay fever } \\
\text { and fever }\end{array}$ & $\begin{array}{l}\text { EST sequencing } \\
\text { and gene } \\
\text { expression } \\
\text { profiling }\end{array}$ & $\begin{array}{l}\text { Park et al. } \\
\text { (2014) }\end{array}$ \\
\hline $\begin{array}{l}\text { Veratrilla } \\
\text { baillonii }\end{array}$ & $\begin{array}{l}\text { Treatment of liver- } \\
\text { related diseases }\end{array}$ & $\begin{array}{l}\text { De novo } \\
\text { transcriptome } \\
\text { assembly; SSR } \\
\text { marker discovery }\end{array}$ & $\begin{array}{l}\text { Wang et al. } \\
(2015 a, b)\end{array}$ \\
\hline $\begin{array}{l}\text { Veratrum } \\
\text { californicum }\end{array}$ & $\begin{array}{l}\text { treatment for various } \\
\text { kinds of cancers }\end{array}$ & $\begin{array}{l}\text { Elucidation of } \\
\text { steroid alkaloid } \\
\text { biosynthesis }\end{array}$ & $\begin{array}{l}\text { Augustin et al. } \\
\text { (2015) }\end{array}$ \\
\hline $\begin{array}{l}\text { Withania } \\
\text { somnifera }\end{array}$ & $\begin{array}{l}\text { Treatment for tumors, } \\
\text { tubercular glands, } \\
\text { carbuncles, ulcers, } \\
\text { burns and wounds }\end{array}$ & $\begin{array}{l}\text { Analysis of the } \\
\text { salicylic acid } \\
\text { induced leaf } \\
\text { transcriptome; } \\
\text { analysis of } \\
\text { withanolide } \\
\text { specific genes to } \\
\text { elucidate } \\
\text { chemotype as well } \\
\text { as tissue specific } \\
\text { withanolide } \\
\text { biosynthesis }\end{array}$ & $\begin{array}{l}\text { Dasgupta et al. } \\
\text { (2014); Gupta } \\
\text { et al. (2013), } \\
\text { (2015) }\end{array}$ \\
\hline $\begin{array}{l}\text { Zantedeschia } \\
\text { aethiopica }\end{array}$ & Antibacterial & $\begin{array}{l}\text { Characterization } \\
\text { of the molecular } \\
\text { and physiological } \\
\text { defense aspects }\end{array}$ & $\begin{array}{l}\text { de Souza } \\
\text { Cândido et al. } \\
\text { (2014) }\end{array}$ \\
\hline
\end{tabular}

In another study, a comprehensive view of seabuckthorn transcriptome from leaf and root tissues has been provided by Ghangal et al. (2013). They employed next generation massive parallel sequencing technology (Illumina Hiseq 2000) and de novo assembly to gain a comprehensive view of the seabuckthorn transcriptome. The optimization of de novo assembly of short reads were also performed with six assembly tools with two 
different approaches to assembled 86,253,874 high quality short reads. Short read assembly yielded 88,297 transcripts ( $\geq 100 \mathrm{bp}$ ), representing about $53 \mathrm{Mb}$ of seabuckthorn transcriptome. The average length of transcripts was $610 \mathrm{bp}$, N50 length $1198 \mathrm{bp}$ and 91\% of the short reads uniquely mapped back to seabuckthorn transcriptome. Among various strategy using different software for de novo assembly, removal of redundancy in short read dataset prior to assembly by short read assembler ABySS following additive k-mer approach was found suitable. Subsequent assembly by long read assembler TGICL yielded the optimum assembly. On the basis of sequence homology significant sequence similarity was shown between Vitis vinifera (grapes) and seabuckthorn. Further, BLAST2GO tool was used to assign gene ontology (GO) terms. In all, 38,830 transcripts had at least one GO term associated with each of them representing $43.9 \%$ of the seabuckthorn transcriptome. In the category of biological process, the largest groups were "primary metabolic process", "cellular metabolic process" and "biosynthetic process" suggesting the abundance of secondary metabolite and other biologically active compounds metabolism pathways in sebauckthorn. Moreover, presence of groups like "cellular response to stimulus", "response to external stimulus", "response to biotic stimulus", response to endogenous stimulus", "response to abiotic stimulus" and "response to stress" in the dataset indicated that a large number of transcripts are expressed in response to environmental stresses (Fig. 2) In the category of molecular function, transcripts with "catalytic activity”, "protein binding” and "nucleotide binding" formed the largest groups. The seabuckthorn transcriptome generated in this study was also screened for the presence of transcription factors and a total of 7421 putative seabuckthorn transcription factor genes, distributed in at least 80 different families, were identified representing $8.4 \%$ of seabuckthorn transcripts. The most frequent transcription factors represented C3H, MADS, bHLH, NAC, and FAR1 families. Next, microsatellites or simple sequence repeats (SSR) were mined from NGS based transcriptome data of seabuckthorn (Jain et al. 2014). The study reported 7.69\% of 88,297 transcripts harbored 
microsatellite repeats with an average of one microsatellite per $6.704 \mathrm{~Kb}$ of seabuckthorn transcriptome. Among various repeats dinucleotide were found most abundant followed by trinucleotide repeats. Further, in coding region microsatellites were densely populated followed by $3^{\prime}$ and $5^{\prime}$ untranslated regions (UTRs). AG and AAG type repeats most frequently occurred in seabuckthorn transcriptome. On the basis of GO terms, $48.81 \%$ microsatellites possess unigenes assigned with at least one GO term to assess associations between microsatellite and biological role of known genes (Fig. 3). In "biological process" category, majority of the unigenes were involved in metabolic processes followed by biosynthetic processes, and responses to various stresses (Fig. 3a), again supported the presence of abundant secondary metabolites in seabuckthorn. However, other important processes like transcription and transport were also recorded. For the cellular components category, majority of the unigenes were found to be related to plastid followed by protein complex and cytoplasm (Fig. 3b). When concentrating on molecular function category, majority of unigenes were assigned to protein binding followed by nucleotide binding (Fig. 3c). Among all 25 unigene specific microsatellites were assessed on the basis of polymorphism(s) detected in 18 seabuckthorn collections from Leh (India). The major findings of the study include the microsatellite data-set which can be used in future breeding and molecular biology research projects in seabuckthorn and other medicinal plants.

\section{Fig. 2}

Gene ontology classification of seabuckthorn transcripts on the basis of their role in biological processes 


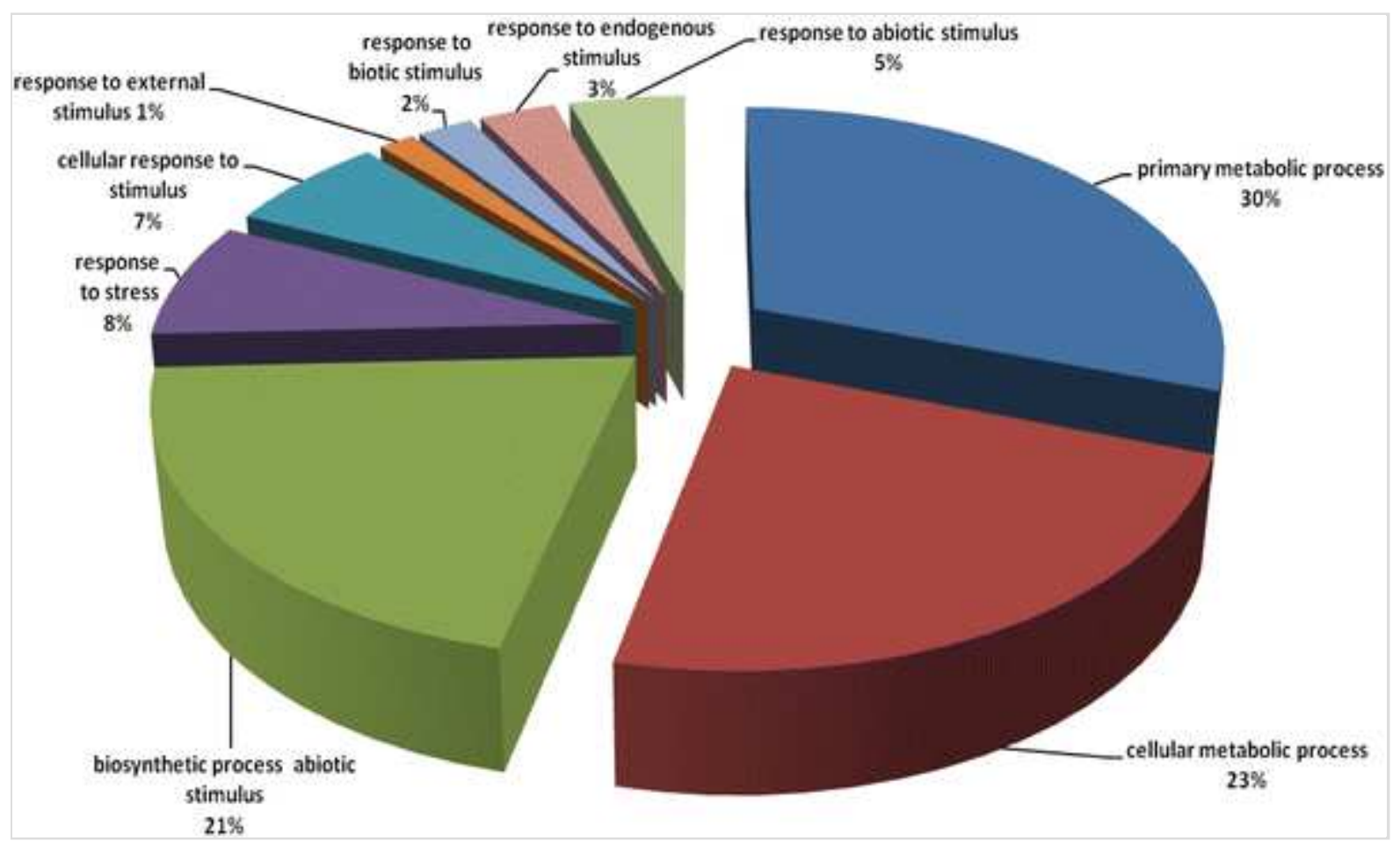

Fig. 3

Gene ontology annotation of microsatellite carrying seabuckthorn unigenes a Biological process; b cellular component, and $\mathbf{c}$ molecular function
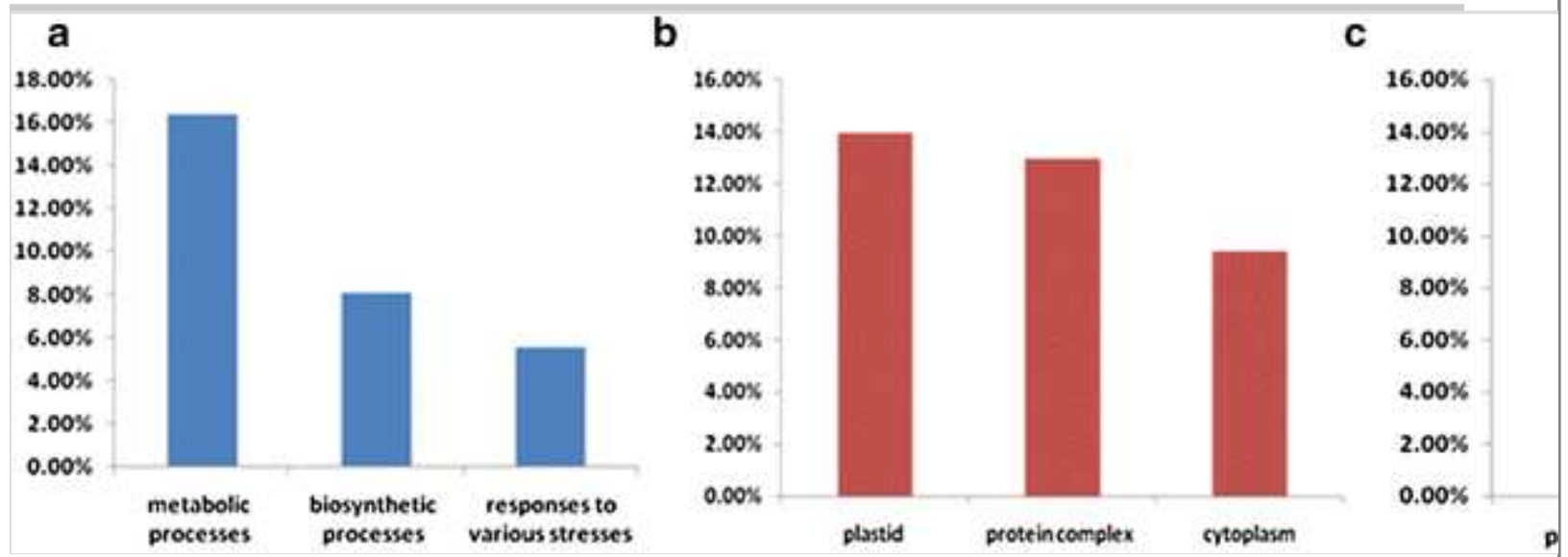

AQ1

Seabuckthorn besides having medicinal and nutritional value also possesses ecological importance. It has the ability to sustain growth in harsh environmental conditions such as extreme temperatures, drought and 
salinity. We employed DeepSAGE, a tag based NGS approach using Illumina Hiseq 2000 platform, to identify differentially expressed genes under cold and freeze stress in seabuckthorn (Chaudhary and Sharma 2015). The study reported 11,922 differentially expressed genes (DEGs) including 6539 up regulated and 5383 down regulated genes in response to cold and freeze stress in seabuckthorn. DEGs generated in the study were further mapped back to existing seabuckthorn transcriptome having 88,297 putative unigenes (Ghangal et al. 2013), and identified 428 cold and freeze stress responsive DEGs. Moreover, expression of 22 DEGs selected from DeepSAGE datasets were validated using qRT-PCR in support of DeepSAGE results. The major finding of the study provided comprehensive global gene expression profile of seabuckthorn under cold and freeze stresses. The data generated could also serve as a valuable resource to develop abiotic stress tolerant transgenic plants.

\section{Conclusion}

Medicinal plants are known to human history for their therapeutic potentials. Safer use of herbal based medicine than the synthetic drugs attracts the masses towards using more and more phytomedicines. Recent advances in NGS technologies have offered cost and labor efficient opportunities to explore medicinal plants at genomic and transcriptomic levels. Enormous genome/transcriptome sequence data-sets of various medicinal plants have been generated in recent past. Subsequently, these data-sets could serve as valuable resources for the selection of candidate genes involved in biosynthesis of biologically active phytocompounds. Such genes may ultimately be explored for the development of transgenic medicinal plants with enhanced therapeutic potentials. Though the NGS based research on important medicinal plants has already accelerated, implementation of NGS technologies is required for other plants which have therapeutic potentials and whose genome/transcriptome are not explored yet.

\section{Acknowledgements}


The authors acknowledge the financial support provided by the Department of Biotechnology (DBT), Government of India.

\section{References}

Ahmed, S., Zhan, C., Yang, Y., Wang, X., Yang, T., Zhao, Z., et al. (2016). The transcript profile of a traditional Chinese medicine, Atractylodes lancea, revealing its sesquiterpenoid biosynthesis of the major active components. PLoS One, 11(3), e0151975.

Annadurai, R. S., Neethiraj, R., Jayakumar, V., Damodaran, A. C., Rao, S. N., Katta, M. A., et al. (2013). De novo transcriptome assembly (NGS) of Curcuma longa L. rhizome reveals novel transcripts related to anticancer and antimalarial terpenoids. PLoS One, 8(2), e56217.

Augustin, M. M., Ruzicka, D. R., Shukla, A. K., Augustin, J. M., Starks, C. M., O’Neil-Johnson, M., et al. (2015). Elucidating steroid alkaloid biosynthesis in Veratrum californicum: Production of verazine in Sf9 cells. The Plant Journal, 82(6), 991-1003.

Berka, J., Chen, Y. J., Leamon, J. H., Lefkowitz, S., Lohman, K. L., Makhijani, V. B., et al. (2010). Bead emulsion nucleic acid amplification. U.S. Patent No. 7,842,457. Washington, DC: U.S. Patent and Trademark Office.

Cakır, Ö., Turgut-Kara, N., Arı, Ş., \& Zhang, B. (2015). De novo transcriptome assembly and comparative analysis elucidate complicated mechanism regulating Astragalus chrysochlorus response to selenium stimuli. PLoS One, 10(10), e0135677.

Chagné, D., Crowhurst, R. N., Pindo, M., Thrimawithana, A., Deng, C., Ireland, H., et al. (2014). The draft genome sequence of European pear (Pyrus communis L. 'Bartlett'). PLoS One, 9(4), e92644. 
Chaudhary, S., \& Sharma, P. C. (2015). DeepSAGE based differential gene expression analysis under cold and freeze stress in seabuckthorn (Hippophae rhamnoides L.). PLoS One, 10(3), e0121982.

Chen, R. B., Liu, J. H., Xiao, Y., Zhang, F., Chen, J. F., Ji, Q., et al. (2015). Deep sequencing reveals the effect of MeJA on scutellarin biosynthesis in Erigeron breviscapus. PLoS One, 10(12), e0143881.

Chen, S., Xiang, L., Guo, X., \& Li, Q. (2011). An introduction to the medicinal plant genome project. Frontiers of Medicine, 5(2), 178-184.

Dasgupta, M. G., George, B. S., Bhatia, A., \& Sidhu, O. P. (2014). Characterization of Withania somnifera leaf transcriptome and expression analysis of pathogenesis-related genes during salicylic acid signaling. PLoS One, 9(4), e94803.

de Magalhaes, J. P., Finch, C. E., \& Janssens, G. (2010). Next-generation sequencing in aging research: emerging applications, problems, pitfalls and possible solutions. Ageing Research Reviews, 9(3), 315-323.

de Souza Cândido, E., da Rocha Fernandes, G., de Alencar, S. A., de Freitas Lima, S. M., de Jesus Miranda, V., Porto, W. F., et al. (2014). Shedding some light over the floral metabolism by arum lily (Zantedeschia aethiopica) spathe de novo transcriptome assembly. PLoS One, 9(3), e90487.

Fatima, T., Snyder, C. L., Schroeder, W. R., Cram, D., Datla, R., Wishart, D., et al. (2012). Fatty acid composition of developing sea buckthorn (Hippophae rhamnoides L.) berry and the transcriptome of the mature seed. PLoS One, 7(4), e34099.

Gahlan, P., Singh, H. R., Shankar, R., Sharma, N., Kumari, A., Chawla, V., et al. (2012). De novo sequencing and characterization of Picrorhiza 
kurrooa transcriptome at two temperatures showed major transcriptome adjustments. BMC Genomics, 13(1), 1-21.

Galla, G., Vogel, H., Sharbel, T. F., \& Barcaccia, G. (2015). De novo sequencing of the Hypericum perforatum L. flower transcriptome to identify potential genes that are related to plant reproduction sensu lato. BMC Genomics, 16(1), 1-22.

Gao, J. P., Wang, D., Cao, L. Y., \& Sun, H. F. (2015). Transcriptome sequencing of Codonopsis pilosula and identification of candidate genes involved in polysaccharide biosynthesis. PLoS One, 10(2), e0117342.

Garg, A., Agrawal, L., Misra, R. C., Sharma, S., \& Ghosh, S. (2015). Andrographis paniculata transcriptome provides molecular insights into tissue-specific accumulation of medicinal diterpenes. BMC Genomics, 16(1), 1-16.

Geetha, S., Jayamurthy, P., Pal, K., Pandey, S., Kumar, R., \& Sawhney, R. C. (2008). Hepatoprotective effects of sea buckthorn (Hippophae rhamnoides L.) against carbon tetrachloride induced liver injury in rats. Journal of the Science of Food and Agriculture, 88(9), 1592-1597.

Ghangal, R., Chaudhary, S., Jain, M., Purty, R. S., \& Sharma, P. C. (2013). Optimization of de novo short read assembly of seabuckthorn (Hippophae rhamnoides L.) transcriptome. PLoS One, 8(8), e72516.

Góngora-Castillo, E., \& Buell, C. R. (2013). Bioinformatics challenges in de novo transcriptome assembly using short read sequences in the absence of a reference genome sequence. Natural Product Reports, 30(4), 490-500.

Groves, R. A., Hagel, J. M., Zhang, Y., Kilpatrick, K., Levy, A., Marsolais, F., et al. (2015). Transcriptome profiling of khat (Catha 
edulis) and Ephedra sinica reveals gene candidates potentially involved in amphetamine-type alkaloid biosynthesis. PLoS One, 10(3), e0119701.

Guo, X., Li, Y., Li, C., Luo, H., Wang, L., Qian, J., et al. (2013). Analysis of the Dendrobium officinale transcriptome reveals putative alkaloid biosynthetic genes and genetic markers. Gene, 527(1), 131-138.

Guo, S., Zheng, Y., Joung, J. G., Liu, S., Zhang, Z., Crasta, O. R., et al. (2010). Transcriptome sequencing and comparative analysis of cucumber flowers with different sex types. BMC Genomics, 11(1), $1-13$.

Gupta, P., Goel, R., Agarwal, A. V., Asif, M. H., Sangwan, N. S., Sangwan, R. S., et al. (2015). Comparative transcriptome analysis of different chemotypes elucidates withanolide biosynthesis pathway from medicinal plant Withania somnifera. Scientific Reports, 5, 1-13.

Gupta, P., Goel, R., Pathak, S., Srivastava, A., Singh, S. P., Sangwan, R. S., et al. (2013). De novo assembly, functional annotation and comparative analysis of Withania somnifera leaf and root transcriptomes to identify putative genes involved in the withanolides biosynthesis. PLoS One, 8(5), e62714.

Hao, D. C., Chen, S. L., Xiao, P. G., \& Liu, M. (2012). Application of high-throughput sequencing in medicinal plant transcriptome studies. Drug Development Research, 73(8), 487-498.

He, M., Wang, Y., Hua, W., Zhang, Y., \& Wang, Z. (2012). De novo sequencing of Hypericum perforatum transcriptome to identify potential genes involved in the biosynthesis of active metabolites. PLoS One, 7(7), e42081. 
Hua, W., Zheng, P., He, Y., Cui, L., Kong, W., \& Wang, Z. (2014). An insight into the genes involved in secoiridoid biosynthesis in Gentiana macrophylla by RNA-seq. Molecular Biology Reports, 41(7), 4817-4825.

Huang, X., Jing, Y., Liu, D. J., Yang, B. Y., Chen, H., \& Li, M. (2016). Whole-transcriptome sequencing of Pinellia ternata using the Illumina platform. Genetics and Molecular Research, 15(2), 1-14.

Jain, A., Chaudhary, S., \& Sharma, P. C. (2014). Mining of microsatellites using next generation sequencing of seabuckthorn (Hippophae rhamnoides L.) transcriptome. Physiology and Molecular Biology of Plants, 20(1), 115-123.

Jayakodi, M., Lee, S. C., Lee, Y. S., Park, H. S., Kim, N. H., Jang, W., et al. (2015). Comprehensive analysis of Panax ginseng root transcriptomes. BMC Plant Biology, 15(1), 1-12.

Kalra, S., Puniya, B. L., Kulshreshtha, D., Kumar, S., Kaur, J., Ramachandran, S., et al. (2013). De novo transcriptome sequencing reveals important molecular networks and metabolic pathways of the plant, Chlorophytum borivilianum. PLoS One, 8(12), e83336.

Kim, H. J., Jung, J., Kim, M. S., Lee, J. M., Choi, D., \& Yeam, I. (2015). Molecular marker development and genetic diversity exploration by RNA-seq in Platycodon grandiflorum. Genome, 58(10), 441-451.

Kotwal, S., Kaul, S., Sharma, P., Gupta, M., Shankar, R., Jain, M., et al. (2016). De novo transcriptome analysis of medicinally important Plantago ovata using RNA-Seq. PLoS One, 11(3), e0150273.

Krishnan, N. M., Pattnaik, S., Jain, P., Gaur, P., Choudhary, R., Vaidyanathan, S., et al. (2012). A draft of the genome and four 
transcriptomes of a medicinal and pesticidal angiosperm Azadirachta indica. BMC Genomics, 13(1), 1-13.

Lai, P. K., \& Roy, J. (2004). Antimicrobial and chemopreventive properties of herbs and spices. Current Medicinal Chemistry, 11(11), 1451-1460.

Li, D. M., Zhao, C. Y., Liu, X. R., Liu, X. F., Lin, Y. J., Liu, J. W., et al. (2015). De novo assembly and characterization of the root transcriptome and development of simple sequence repeat markers in Paphiopedilum concolor. Genetics and Molecular Research, 14(2), 6189-6201.

Li, C., Zhu, Y., Guo, X., Sun, C., Luo, H., Song, J., et al. (2013). Transcriptome analysis reveals ginsenosides biosynthetic genes, microRNAs and simple sequence repeats in Panax ginseng C. A. Meyer. BMC Genomics, 14(1), 1-11.

Liu, L., Li, Y., Li, S., Hu, N., He, Y., Pong, R., et al. (2012). Comparison of next-generation sequencing systems. Journal of Biomedicine and Biotechnology, 2012(2012), 1-11.

Liu, X. B., Ma, L., Zhang, A. H., Zhang, Y. H., Jiang, J., Ma, W., et al. (2014a). High-throughput analysis and characterization of Astragalus membranaceus transcriptome using 454 GS FLX. PLoS One, 9(5), e95831.

Liu, H., Wu, W., Hou, K., Chen, J., \& Zhao, Z. (2016). Deep sequencing reveals transcriptome re-programming of Polygonum multiflorum thunb. roots to the elicitation with methyl jasmonate. Molecular Genetics and Genomics, 291(1), 337-348.

Liu, M. M., Xing, Y. M., Zhang, D. W., \& Guo, S. X. (2015a).

Transcriptome analysis of genes involved in defence response in 
Polyporus umbellatus with Armillaria mellea infection. Scientific Reports, 5, 1-13.

Liu, M. H., Yang, B. R., Cheung, W. F., Yang, K. Y., Zhou, H. F., Kwok, J. S. L., et al. (2015b). Transcriptome analysis of leaves, roots and flowers of Panax notoginseng identifies genes involved in ginsenoside and alkaloid biosynthesis. BMC Genomics, 16(1), 1-12.

Liu, M. J., Zhao, J., Cai, Q. L., Liu, G. C., Wang, J. R., Zhao, Z. H., et al. (2014b). The complex jujube genome provides insights into fruit tree biology. Nature Communications, 5, 1-12.

Lulin, H., Xiao, Y., Pei, S., Wen, T., \& Shangqin, H. (2012). The first Illumina-based de novo transcriptome sequencing and analysis of safflower flowers. PLoS One, 7(6), e38653.

Ma, C. H., Gao, Z. J., Zhang, J. J., Zhang, W., Shao, J. H., Hai, M. R., et al. (2016). Candidate genes involved in the biosynthesis of triterpenoid saponins in Platycodon grandiflorum identified by transcriptome analysis. Frontiers in plant science, 7, 1-14.

MacLean, D., Jones, J. D., \& Studholme, D. J. (2009). Application of 'next-generation' sequencing technologies to microbial genetics. Nature Reviews Microbiology, 7(4), 287-296.

Mardis, E. R. (2008). Next-generation DNA sequencing methods. Annual Reviews of Genomics and Human Genetics, 9, 387-402.

Mardis, E. R. (2013). Next-generation sequencing platforms. Annual Review of Analytical Chemistry, 6, 287-303.

Martínez-García, P. J., Crepeau, M. W., Puiu, D., Gonzalez-Ibeas, D., Whalen, J., Stevens, K. A., et al. (2016). The walnut (Juglans regia) genome sequence reveals diversity in genes coding for the biosynthesis 
of nonstructural polyphenols. The Plant Journal, 87(5), 507-532.

Maxam, A. M., \& Gilbert, W. (1977). A new method for sequencing DNA. Proceedings of the National Academy of Sciences, 74(2), 560-564.

Mazumdar, A. B., \& Chattopadhyay, S. (2015). Sequencing, de novo assembly, functional annotation and analysis of Phyllanthus amarus leaf transcriptome using the Illumina platform. Frontiers in plant science, 6, 1-22.

Meena, S., Kumar, S. R., Rao, D. V., Dwivedi, V., Shilpashree, H. B., Rastogi, S., et al. (2016). De novo sequencing and analysis of lemongrass transcriptome provide first insights into the essential oil biosynthesis of aromatic grasses. Frontiers in Plant Science, 7, 1-15.

Metzker, M. L. (2010). Sequencing technologies-the next generation. Nature Reviews Genetics, 11(1), 31-46.

Ming, R., VanBuren, R., Liu, Y., Yang, M., Han, Y., Li, L. T., et al. (2013). Genome of the long-living sacred lotus (Nelumbo nucifera Gaertn.). Genome Biology, 14(5), 1-11.

Muranaka, T., \& Saito, K. (2013). Phytochemical genomics on the way. Plant and Cell Physiology, 54(5), 645-646.

Muriira, N. G., Xu, W., Muchugi, A., Xu, J., \& Liu, A. (2015). De novo sequencing and assembly analysis of transcriptome in the Sodom apple (Calotropis gigantea). BMC Genomics, 16(1), 1-15.

Park, N. I., Choi, I. Y., Choi, B. S., Kim, Y. S., Lee, M. Y., \& Park, S. U. (2014). EST sequencing and gene expression profiling in Scutellaria baicalensis. EXCLI Journal, 13, 392-401. 
Qi, J., Sun, P., Liao, D., Sun, T., Zhu, J., \& Li, X. (2015).

Transcriptomic analysis of American ginseng seeds during the dormancy release process by RNA-Seq. PLoS One, 10(3), e0118558.

Qin, C., Yu, C., Shen, Y., Fang, X., Chen, L., Min, J., et al. (2014). Whole-genome sequencing of cultivated and wild peppers provides insights into Capsicum domestication and specialization. Proceedings of the National Academy of Sciences, 111(14), 5135-5140.

Quail, M. A., Smith, M., Coupland, P., Otto, T. D., Harris, S. R., Connor, T. R., et al. (2012). A tale of three next generation sequencing platforms: comparison of Ion Torrent, Pacific Biosciences and Illumina MiSeq sequencers. BMC Genomics, 13(1), 1-13.

Rai, A., Kamochi, H., Suzuki, H., Nakamura, M., Takahashi, H., Hatada, T., et al. (2016). De novo transcriptome assembly and characterization of nine tissues of Lonicera japonica to identify potential candidate genes involved in chlorogenic acid, luteolosides, and secoiridoid biosynthesis pathways. Journal of Natural Medicines, $1-15$.

Ramilowski, J. A., Sawai, S., Seki, H., Mochida, K., Yoshida, T., Sakurai, T., et al. (2013). Glycyrrhiza uralensis transcriptome landscape and study of phytochemicals. Plant and Cell Physiology, 54(5), 697-710.

Rastogi, S., Meena, S., Bhattacharya, A., Ghosh, S., Shukla, R. K., Sangwan, N. S., et al. (2014). De novo sequencing and comparative analysis of holy and sweet basil transcriptomes. BMC Genomics, 15(1), $1-18$.

Reddy, N. R. R., Mehta, R. H., Soni, P. H., Makasana, J., Gajbhiye, N. A., Ponnuchamy, M., et al. (2015). Next generation sequencing and transcriptome analysis predicts biosynthetic pathway of sennosides 
from Senna (Cassia angustifolia Vahl.), a non-model plant with potent laxative properties. PLoS One, 10(6), e0129422.

Rusk, N. (2011). Torrents of sequence. Nature Methods, 8(1), 44.

Sanger, F., Nicklen, S., \& Coulson, A. R. (1977). DNA sequencing with chain-terminating inhibitors. Proceedings of the National Academy of Sciences, 74(12), 5463-5467.

Sangwan, R. S., Tripathi, S., Singh, J., Narnoliya, L. K., \& Sangwan, N. S. (2013). De novo sequencing and assembly of Centella asiatica leaf transcriptome for mapping of structural, functional and regulatory genes with special reference to secondary metabolism. Gene, 525(1), 58-76.

Schadt, E. E., Turner, S., \& Kasarskis, A. (2010). A window into thirdgeneration sequencing. Human Molecular Genetics, 19(R2), R227-R240.

Schneider, G. F., \& Dekker, C. (2012). DNA sequencing with nanopores. Nature Biotechnology, 30(4), 326-328.

Sharma, S., \& Shrivastava, N. (2016). Renaissance in phytomedicines: promising implications of NGS technologies. Planta, 244(1), 19-38.

Shendure, J., \& Ji, H. (2008). Next-generation DNA sequencing. Nature Biotechnology, 26(10), 1135-1145.

Shi, S. G., Yang, M., Zhang, M., Wang, P., Kang, Y. X., \& Liu, J. J. (2014). Genome-wide transcriptome analysis of genes involved in flavonoid biosynthesis between red and white strains of Magnolia sprengeri pamp. BMC Genomics, 15(1), 1-11.

Singh, V., Mörsel, J. T., Singh, V., Yang, B., Kallio, H., Bala, M., et al. (2006). Development and commercialization of seabuckthorn: a 
German experience. Seabuckthorn (Hippophae L.). A multipurpose wonder plant. Vol II: Biochemistry and Pharmacology, 576-584.

Singh, R., Ong-Abdullah, M., Low, E. T. L., Manaf, M. A. A., Rosli, R., Nookiah, R., et al. (2013). Oil palm genome sequence reveals divergence of interfertile species in Old and New worlds. Nature, 500(7462), 335-339.

Subramaniyam, S., Mathiyalagan, R., Natarajan, S., Kim, Y. J., Jang, M. G., Park, J. H., et al. (2014). Transcript expression profiling for adventitious roots of Panax ginseng Meyer. Gene, 546(1), 89-96.

Sumner, L. W., Lei, Z., Nikolau, B. J., \& Saito, K. (2015). Modern plant metabolomics: Advanced natural product gene discoveries, improved technologies, and future prospects. Natural Product Reports, 32(2), 212-229.

Sun, C., Li, Y., Wu, Q., Luo, H., Sun, Y., Song, J., et al. (2010). De novo sequencing and analysis of the American ginseng root transcriptome using a GS FLX Titanium platform to discover putative genes involved in ginsenoside biosynthesis. BMC Genomics, 11(1), $1-12$.

Sun, P., Song, S., Zhou, L., Zhang, B., Qi, J., \& Li, X. (2012a). Transcriptome analysis reveals putative genes involved in iridoid biosynthesis in Rehmannia glutinosa. International Journal of Molecular Sciences, 13(10), 13748-13763.

Sun, C., Yu, G., Bao, M., Zheng, B., \& Ning, G. (2014). Biological pattern and transcriptomic exploration and phylogenetic analysis in the odd floral architecture tree: Helwingia willd. BMC Research Notes, $7(1), 1-12$.

Sun, X., Zhou, S., Meng, F., \& Liu, S. (2012b). De novo assembly and 
characterization of the garlic (Allium sativum) bud transcriptome by Illumina sequencing. Plant Cell Reports, 31(10), 1823-1828.

Suryakumar, G., \& Gupta, A. (2011). Medicinal and therapeutic potential of Sea buckthorn (Hippophae rhamnoides L.). Journal of Ethnopharmacology, 138(2), 268-278.

Tao, L., Zhao, Y., Wu, Y., Wang, Q., Yuan, H., Zhao, L., et al. (2016). Transcriptome profiling and digital gene expression by deep sequencing in early somatic embryogenesis of endangered medicinal Eleutherococcus senticosus Maxim. Gene, 578(1), 17-24.

Thompson, J. F., \& Milos, P. M. (2011). The properties and applications of single-molecule DNA sequencing. Genome Biology, 12(2), 1-10.

Tian, H., Xu, X., Zhang, F., Wang, Y., Guo, S., Qin, X., et al. (2015). Analysis of Polygala tenuifolia transcriptome and description of secondary metabolite biosynthetic pathways by Illumina sequencing. International Journal of Genomics, 2015, 1-11.

Unamba, C. I., Nag, A., \& Sharma, R. K. (2015). Next generation sequencing technologies: The doorway to the unexplored genomics of non-model plants. Frontiers in Plant Science, 6, 1-16.

Upadhyay, A. K., Chacko, A. R., Gandhimathi, A., Ghosh, P., Harini, K., Joseph, A. P., et al. (2015). Genome sequencing of herb Tulsi (Ocimum tenuiflorum) unravels key genes behind its strong medicinal properties. BMC Plant Biology, 15(1), 1-20.

Upadhyay, S., Phukan, U. J., Mishra, S., \& Shukla, R. K. (2014). De novo leaf and root transcriptome analysis identified novel genes involved in steroidal sapogenin biosynthesis in Asparagus racemosus. BMC Genomics, 15(1), 1-13. 
van Bakel, H., Stout, J. M., Cote, A. G., Tallon, C. M., Sharpe, A. G., Hughes, T. R., et al. (2011). The draft genome and transcriptome of Cannabis sativa. Genome Biology, 12(10), 1-13.

Van Moerkercke, A., Fabris, M., Pollier, J., Baart, G. J., Rombauts, S., Hasnain, G., et al. (2013). CathaCyc, a metabolic pathway database built from Catharanthus roseus RNA-Seq data. Plant and Cell Physiology, 54(5), 673-685.

Wang, G., Du, X., Ji, J., Guan, C., Li, Z., \& Josine, T. L. (2015a). De novo characterization of the Lycium chinense Mill. leaf transcriptome and analysis of candidate genes involved in carotenoid biosynthesis. Gene, 555(2), 458-463.

Wang, Z., Gerstein, M., \& Snyder, M. (2009). RNA-Seq: A revolutionary tool for transcriptomics. Nature Reviews Genetics, 10(1), $57-63$.

Wang, Y., Hua, W., Wang, J., Hannoufa, A., Xu, Z., \& Wang, Z. (2013). Deep sequencing of Lotus corniculatus L. reveals key enzymes and potential transcription factors related to the flavonoid biosynthesis pathway. Molecular Genetics and Genomics, 288(3-4), 131-139.

Wang, L., Wang, Z., Chen, J., Liu, C., Zhu, W., Wang, L., et al. (2015b). De novo transcriptome assembly and development of novel microsatellite markers for the traditional chinese medicinal herb, Veratrilla baillonii Franch (Gentianaceae). Evolutionary Bioinformatics Online, 11(39), 1-7.

Wu, D., Austin, R. S., Zhou, S., \& Brown, D. (2013). The root transcriptome for North American ginseng assembled and profiled across seasonal development. BMC Genomics, 14(1), 1-14.

Wu, B., Suo, F., Lei, W., \& Gu, L. (2014). Comprehensive analysis of 
alternative splicing in Digitalis purpurea by strand-specific RNA-Seq. PLoS One, 9(8), e106001.

Wu, B., Wang, M., Ma, Y., Yuan, L., \& Lu, S. (2012). High-throughput sequencing and characterization of the small RNA transcriptome reveal features of novel and conserved microRNAs in Panax ginseng. PLoS One, 7(9), e44385.

Xu, Z., Peters, R. J., Weirather, J., Luo, H., Liao, B., Zhang, X., et al. (2015). Full-length transcriptome sequences and splice variants obtained by a combination of sequencing platforms applied to different root tissues of Salvia miltiorrhiza and tanshinone biosynthesis. The Plant Journal, 82(6), 951-961.

Yang, L., Ding, G., Lin, H., Cheng, H., Kong, Y., Wei, Y., et al. (2013). Transcriptome analysis of medicinal plant Salvia miltiorrhiza and identification of genes related to tanshinone biosynthesis. PLoS One, 8(11), e80464.

Yang, Y. H., Li, M. J., Li, X. Y., Chen, X. J., Lin, W. X., \& Zhang, Z. Y. (2015). Transcriptome-wide identification of the genes responding to replanting disease in Rehmannia glutinosa L. roots. Molecular Biology Reports, 42(5), 881-892.

Yuan, Y., Song, L., Li, M., Liu, G., Chu, Y., Ma, L., et al. (2012).

Genetic variation and metabolic pathway intricacy govern the active compound content and quality of the Chinese medicinal plant Lonicera japonica thunb. BMC Genomics, 13(1), 1-20.

Zhang, X., Allan, A. C., Li, C., Wang, Y., \& Yao, Q. (2015a). De novo assembly and characterization of the transcriptome of the Chinese medicinal herb, Gentiana rigescens. International Journal of Molecular Sciences, 16(5), 11550-11573. 
Zhang, Q., Chen, W., Sun, L., Zhao, F., Huang, B., Yang, W., et al. (2012). The genome of Prunus mume. Nature Communications, 3, 1318-1325.

Zhang, F., Gao, Q., Khan, G., Luo, K., \& Chen, S. (2014). Comparative transcriptome analysis of aboveground and underground tissues of Rhodiola algida, an important ethno-medicinal herb endemic to the Qinghai-Tibetan Plateau. Gene, 553(2), 90-97.

Zhang, G. H., Jiang, N. H., Song, W. L., Ma, C. H., Yang, S. C., \& Chen, J. W. (2016a). De novo sequencing and transcriptome analysis of Pinellia ternata identify the candidate genes involved in the biosynthesis of benzoic acid and ephedrine. Frontiers in Plant Science, 7, 1-14.

Zhang, S., Wu, Y., Jin, J., Hu, B., Zeng, W., Zhu, W., et al. (2015b). De novo characterization of Panax japonicus C. A. Mey transcriptome and genes related to triterpenoid saponin biosynthesis. Biochemical and Biophysical Research Communications, 466(3), 450-455.

Zhang, G. Q., Xu, Q., Bian, C., Tsai, W. C., Yeh, C. M., Liu, K. W., et al. (2016b). The Dendrobium catenatum Lindl. genome sequence provides insights into polysaccharide synthase, floral development and adaptive evolution. Scientific Reports, 6, 1-10.

Zhao, S., Tuan, P. A., Li, X., Kim, Y. B., Kim, H., Park, C. G., et al. (2013). Identification of phenylpropanoid biosynthetic genes and phenylpropanoid accumulation by transcriptome analysis of Lycium chinense. BMC Genomics, 14(1), 802-812.

Zheng, X., Pan, C., Diao, Y., You, Y., Yang, C., \& Hu, Z. (2013). Development of microsatellite markers by transcriptome sequencing in two species of Amorphophallus (Araceae). BMC Genomics, 14(1), $1-11$. 